\title{
Seeing Brands as Humans: Development and Validation of a Brand Anthropomorphism Scale
}

\begin{abstract}
Brand anthropomorphism is recognised as an important construct in marketing, yet it lacks clarity in operationalisation and valid measurement. The objective of this research, therefore, is to develop and validate the brand anthropomorphism scale (BASC). Brand anthropomorphism is defined as the perception of brand as an entity that has analogical human-like features, mental and emotional states that people believe to be distinctively human. It is conceptualised as a multidimensional superordinate construct. Across six studies $(N=1,666)$, this research develops a valid and reliable measure of brand anthropomorphism that has psychometric properties for convergent, discriminant and predictive validity. The results indicate that brand anthropomorphism is a valid predictor of outcomes such as brand trust and brand commitment. Finally, in support of incremental validity, it is identified that the BASC explains variance in brand trust and brand commitment above and beyond the measure of brand anthropomorphism commonly employed in the literature. Theoretical implications for research and implications for practice are also discussed.
\end{abstract}

Keywords: brand anthropomorphism, brand perception, consumer-brand relationships, scale development, scale validation

\section{Introduction}

People's perception of human-like agency extends to targets spanning across various domains including supernatural agents, technological gadgets, nature and animals (Epley, Waytz, \& Cacioppo, 2007). Recent advances in consumer research have demonstrated that people readily humanise or anthropomorphise other entities such as brands (Aggarwal \& McGill, 2012). This is not surprising, given that managers often direct their marketing communications and promotion strategies to foster the meaning of a brand as a human-like entity. This is often achieved by incorporating various combinations of qualities and characteristics that resemble those of people, such as human forms, personality, and the ability to speak, imagine and feel. Those human characteristics can be subtly and implicitly incorporated in brands, products and communications. For example, Pret a Manger depicts fruits and vegetables with facial expressions in their brand packaging and promotional materials. In a similar way, Danone presents some of their health-orientated products in an hourglass shape resembling a human body. Other efforts to depict a brand as a human-like entity involve incorporating human characteristics in an overt and explicit way. A television advertisement for GEIKO, for example, depicts an anthropomorphised gecko imagining how he would reduce the cost of car insurance if he possessed unlimited power. In another example, Amazon Alexa was portrayed losing her voice, imitating a similar human phenomenon. All of those strategies are likely to trigger consumers' perception of brands as living and social entities, with their own human-like characteristics, emotions and thoughts (Kim \& McGill, 2011; Puzakova, Kwak, \& Rocereto, 2013). Most prior studies in marketing literature have investigated the nature of anthropomorphised targets (Kim \& Kramer, 2015; Puzakova \& Kwak, 2017) and downstream consequences of anthropomorphism, such as the extent to which perceiving a brand as a human-like entity would affect consumers' attitudes and evaluations (Aggarwal \& McGill, 2007; Kwak, Puzakova, \& Rocereto, 2015; Landwehr, McGill, \& Herrmann, 2011; Puzakova et al., 2013; Wan, Chen, \& Jin, 2017). However, despite the considerable amount of interest from both practitioners and researchers, no adequate measure of anthropomorphism has been developed specifically for brands.

A significant body of empirical research has measured brand anthropomorphism by utilising measurements with limited psychometric properties that have not been fully reported or analysed (e.g., Chen, Wan, \& Levy, 2017; Wan et al., 2017). Often these measurements are used as simple manipulation checks and are adapted from studies on product anthropomorphism or from other disciplines, and thus they may not be appropriate for the study of specific brand anthropomorphism phenomena. To the best of our knowledge, only one study has attempted to develop a 
scale measuring anthropomorphism in the marketing field (Guido \& Peluso, 2015). However, the study focused on product categorisation and used highly specific items such as "this branded product seems to have a nose" or "this branded product seems to have a human neck" (Guido \& Peluso, 2015, p.10), measuring only one of the possible facets of anthropomorphism. Finally, brand anthropomorphism has been rarely examined in regard to existing brands, operationalisation of the construct being restricted to the laboratory setting.

Accordingly, the key contribution of this study is to develop a multidimensional theory-driven measure of brand anthropomorphism based on existing theoretical conceptualisation. Unlike most previous studies, this study develops a brand-independent measure of anthropomorphism using rigorous psychometric tests for its reliability and validity in theoretical and applied settings. The second contribution of this study is to empirically investigate the predictive validity of the construct by examining the consequential effects of the construct on brand trust and brand commitment. The final contribution of this study is to establish the incremental validity of the scale by investigating the predictive power of the proposed scale in comparison to the proxy measure of brand anthropomorphism commonly employed in the literature.

This study also offers practical implications for marketing practitioners interested in developing brand-consumer relationships through the use of brand anthropomorphism strategies. As demonstrated in the earlier examples, recent industry trends suggest that managers imbue brands with human-like characteristics to establish brand positioning (Kwak, Puzakova, \& Rocereto, 2017). The prevalence of these positioning strategies might be explained by the more favourable attitudes consumers have towards anthropomorphised brands (Aggarwal \& McGill, 2007) and consumers' willingness to connect and form relationships with these brands (Ahn, Kim, \& Aggarwal, 2014; Fournier \& Alvarez, 2012). Given the emerging popularity of brand anthropomorphism, our measure can serve as a practical means for assessing and evaluating the degree to which consumers perceive a brand as a human-like entity.

The remainder of the article is organised as follows. Firstly, we review the literature on anthropomorphism and present a definition of the construct. Then, on the basis of this definition, we develop and validate a higher-order four-dimensional brand anthropomorphism scale (BASC). Our empirical scale development and validation process consists of initial items generation followed by six studies involving (1) assessment of the latent structure of the scale, (2) scale purification and initial validation, (3) final validation and assessment of measurement invariance, (4) tests for discriminant validity, (5) test of predictive validity and assessment of incremental validity, (6) assessment of test-retest reliability.

\section{Conceptualisation}

Although research on anthropomorphism in marketing has only emerged over the last two decades, the concept takes its origin back to Ancient Greece and has been discussed by philosophers ever since. The word anthropomorphism originates from the Greek words "anthropos" (human) and "morphe" (shape or form), and as such, anthropomorphism leads individuals to perceive both physical and abstract entities as they perceive humans. Specifically, anthropomorphism is the phenomenon by which non-human entities are attributed with human-like characteristics, properties, behaviours and mental states that people believe to be uniquely human (Epley et al., 2007). Although perception of mental states in non-human entities (Gray, Gray, \& Wegner, 2007) is a central aspect of anthropomorphism, which subsequently leads to a common operationalisation of the construct as "a particular form of mental state attribution" (Waytz, Cacioppo, \& Epley, 2010, p. 211), it is not exhaustive. Anthropomorphism also includes attributing behavioural characteristics, observable human-like concepts and refined emotional states to non-human agents (Epley et al., 2007; Leyens et al., 2001).

In the marketing literature, the conceptualisation of brand anthropomorphism often adheres to the previously mentioned definition of anthropomorphism (Aggarwal \& McGill, 2012; MacInnis \& Folkes, 2017). Fournier (1998) and Fournier and Alvarez (2012) have argued that for a brand to be a prominent member of consumer-brand relationships, it should be anthropomorphised, in the sense that the brand is perceived as possessing qualities of a human being, capable of thoughtful behaviour, emotionality and feelings. Similarly, Puzakova, Kwak, and Rocereto (2009) define brand anthropomorphism as consumers' perception of brands as "actual human beings with various emotional states, mind, soul, and conscious behaviours that can act as prominent members of social ties" (p. 413). We further review theoretical perspectives of brand anthropomorphism to identify potential dimensions of the construct. 


\subsection{Analogical anthropomorphism}

According to Kim and McGill (2011), one of the distinct forms of brand anthropomorphism is analogical in nature, in which cognitive associations using the human schema are created to structure, reflect and communicate brand characteristics. In this form, anthropomorphism involves the simple description of perceivable similarities in superficial characteristics such as appearance, concepts or behaviour between a brand and people. Attribution of personality to brands (Aaker, 1997) may also be seen as this form of anthropomorphism (Kim \& McGill, 2011). Importantly, people readily recognise both subtle and explicit superficial characteristics incorporated in brands' strategies and communications (Reavey, Puzakova, Larsen Andras, \& Kwak, 2018). A brand depicted in a way that resembles human-like physical characteristics, whether subtly or explicitly, can be perceived and thought of as analogous to a person, and ascribed personality traits, but without really being seen as an actual person with underlying values, thoughts and emotions. Hence, this analogical perception of a brand in human terms mostly depends on the explicit or subtle brand's resemblance to a human (Landwehr et al., 2011).

Both subtle and explicit superficial human-like characteristics embedded in a brand can facilitate the recognition of similarities between the brand and a human, thus fostering the analogous perception of the brand as a human. For example, this can be achieved through visual cues when the brand's features resemble human forms, shapes and faces (Hur, Koo, \& Hofmann, 2015; Romero \& Craig, 2017) or by depicting a brand in typical human actions (Puzakova et al., 2013). Through verbal cues, brands can also foster a brand's meaning as human-like by being labelled as gendered (Avery, 2012), or by using first person in describing a brand (Aggarwal \& McGill, 2007) or closeimplying language (e.g., "we" instead of "you and [the brand]") in the brand's communications (Sela, Wheeler, \& Sarial-Abi, 2012). When consumers make inferences about a brand, the presence of human-like cues increases the likelihood of activating human schema (Puzakova et al., 2013). This impression formation, at the time of the inference process, then drives a general evaluative impression of the entity (Srull \& Wyer, 1989). Thus, the activated human-schema helps to establish and enrich vivid impressions of a brand as a human-like entity. This impression can be retrieved later when needed for further decision-making during different interactions with that brand.

\subsection{Mental states perception in brands}

Another form of brand anthropomorphism brings to light the notion of perceiving a brand as an "absolute and real" person (Kim \& McGill, 2011). In this form, anthropomorphising a brand does not involve mere analogical thinking and perception of superficial human characteristics but rather, perception of a brand as being mindful, in the sense that it has mental states that are essential to being human (Kim \& McGill, 2011; Puzakova et al., 2009). Specifically, this form involves, but is not limited to, perceiving a brand as capable of making moral judgements, engaging in reasoning, forming intentions and experiencing emotions. The process of mental state attribution to a brand is predicted in large part by accessibility and applicability of knowledge about the self and humans. As previously discussed, a brand that incorporates subtle or explicit human characteristics facilitates the activation of human schema. This in turn increases the likelihood of starting the process of mental state attribution to that brand (e.g., Waytz, Gray, Epley, \& Wegner, 2010). Motivational factors such as desire to understand the acts of non-human agents (effectance motivation) and the need for connection and affiliation (sociality motivation) can further increase the likelihood of viewing brands in human-like terms (Epley et al., 2007).

The process of mental state perception might also emerge without morphological, physical or rhetorical resemblance to humans. Among abstract entities, a brand can have intentions and reasoning (Kwak et al., 2015) and may come to life (Aggarwal \& McGill, 2012); a disease can have a humanlike motive to hurt (Kim \& McGill, 2011), and time can have free will (May \& Monga, 2014). Importantly, it is not whether an abstract entity such as a brand (e.g., Dove) can possess mental states and should be treated as human, but rather, whether the brand is anthropomorphised in the consumer's mind. When the brand is believed to have mental qualities, the consumers' evaluations of the brand's actions, and their interactions with the brand can be influenced.

Consumers tend to evaluate some of the actions of the brand based on the extent to which the brand is anthropomorphised. Attribution of mindfulness leads to the perception that the agent's behaviour is under the control of an agent and is in accordance with thoughtful underlying reasons (Caruso, Waytz, \& Epley, 2010). This is because mental qualities such as intentions, cognition and emotions are perceived as crucial in explaining the behaviour and determining blame and responsibility of an independent entity (Bering, 2002). In relation to brands, Kwak et al. (2015) found that the more the brand was perceived as having a mind, the more consumers perceived price increases by that brand as less fair and price decreases as more fair. Similarly, Puzakova et al. (2013) show that viewing 
a brand as having mental states increases the perception of this brand as being responsible and accountable for performing negative actions.

Previous research suggests that perceiving brands as if they have human-like minds can affect, perhaps on a subconscious level, how consumers interact with them. According to Fournier and Alvarez (2012), anthropomorphism is a key mechanism that enables a brand to accomplish the role of an active participant in the consumerbrand interactions and relationships. When consumers anthropomorphise the brand, this promote goals for successful social interaction leading to behaviour that is contrastive or assimilative to the brand image (Aggarwal and McGill, 2012). Additional research demonstrates that attributing human-like mental states to non-human agents facilitates relationship-supportive behaviour. Individuals are more likely to treat anthropomorphised agents as moral entities worthy of concern and care, because they are viewed as beings capable of cognition and emotions (e.g., Tam, Lee, \& Chao, 2013). Ahn, Kim, and Aggarwal (2014) demonstrate that depicting cause-related symbolic entities, such as brands, as having human-like qualities, increased compliance with the social cause message because people wanted to avoid feeling guilty about not helping the anthropomorphised entity.

Popular press and digital media provide additional evidence of mental state attribution to brands. For example, recent headlines such as "brands think like customers but do they feel like them" (Alouche, 2014), "brands think they know who their customers are" (O'Meara, 2019) and "is your brand guilt free" (Belan, 2013) allude to viewing brands as human-like entities with cognitive and feeling capabilities. Often these attributions arise from the usage of the terms brands/companies as synonyms. Nevertheless, the very existence of such headlines points to the attribution of mental state to brands, which can be influenced through anthropomorphic communications. The fact that most of these and similar headlines are of recent origin further highlights the increasing interest in brand anthropomorphism noted earlier, underscoring the validity and timeliness of the current study.

\subsection{Uniquely human mental states}

As the preceding discussion implies, the essence of this form of anthropomorphism is mental state attribution. The defining aspect of those mental states is the extent to which they are unique to humans (Epley, Waytz, Akalis, \& Cacioppo, 2008; Waytz, Cacioppo, et al., 2010). Therefore, the mental qualities that people tend to regard as uniquely human would be a necessary condition for perceiving the brand as a human-like entity. We further review the literature on human uniqueness to identify mental states that would qualify as unique to humans.

From a philosophical viewpoint, the mental states that distinguish humans from other agents are entangled by notions such as metaphysical and moral personhood (DeGrazia, 1997; Moore, 1999). The metaphysical notion postulates that mental states are essential traits that define a person (Dennett, 1988). In this view, an entity can be defined as a person if it possesses complex cognitive capacities, such as rationality, self-reflection, communication and capacity to act freely. On the other hand, the moral personhood notion emphasises moral virtue as an essential aspect in denoting one as an individual being. In this view, in order to qualify as an individual, one must show that they have qualities such as kindness, trustworthiness or sense of honour, the qualities that constitute moral virtue (Sapontzis, 1981). While there are varied opinions as to whether or not metaphysical personhood can simply be a sufficient condition for moral personhood, we consider both notions as important conditions for being human.

Empirical studies that examine lay person's beliefs about humanness support the notion that cognitively complex mental states and emotions are defining characteristics that distinguish humans from non-human agents (Demoulin, Leyens, Paladino, Rodriguez-Torres, et al., 2004; Haslam, Kashima, Loughnan, Shi, \& Suitner, 2008). Also referred to as human uniqueness, those are the characteristics that are not shared with other agents (Haslam, 2006). Findings on dimensions of mind perception (Gray et al., 2007) demonstrate that mental capabilities labelled as agency such as morality, planning and thinking, show strong affinity with human uniqueness (Haslam \& Loughnan, 2014). Similarly, Gray, Waytz and Young (2012) found that agency dimension overlaps with the traits that resemble human uniqueness, further supporting the notion that agentic mental states are viewed as unique to humans. Because agentic mental states are viewed as uniquely human, they are essential conditions in bringing closer the notion of a brand as a human-like entity.

Brand anthropomorphism also entails the perception of distinctively human emotional states (Epley et al., 2007; Puzakova et al., 2009). Considerable research has investigated the extent to which various emotions are understood and perceived as unique to humans (e.g., Demoulin, Leyens, Paladino, Rodriguez-Torres, et al., 2004; Leyens et al., 2001). Uniquely human emotions (e.g., guilt, shame, and remorse to name a few) are considered to be self-conscious, involve complex cognition, morality and are evoked as a result of external factors (Demoulin, Leyens, 
Paladino, Rodriguez-Torres, et al., 2004; Leyens et al., 2001). For instance, the blame evoked as the result of anthropomorphised brand committing a wrongdoing, might trigger the perception that the brand experiences guilt or remorse over the actions that led to the wrongdoings. In this, the brand can be viewed as reflecting on its own actions by applying societal, internal or external perspectives on its behaviours. The perception of the brand as capable of experiencing conscious emotions would emphasise the capability of that brand for complex cognition and morality.

\subsection{Construct definition}

Based on the preceding discussion, brand anthropomorphism is conceptualised as a psychological and perceptual phenomenon and defined as the perception of the brand as an entity that has analogical human-like features, mental and emotional states that people believe are distinctively human.

\subsection{Dimensional structure and higher-order nature}

Building on the conceptualisation of brand anthropomorphism, we initially viewed brand anthropomorphism as a superordinate construct consisting of several distinct yet related substantive components. The superordinate construct was considered because such constructs are more conceptually parsimonious than their individual dimensions and are better predictors of broadly defined outcomes (Edwards, 2001). Hence, it was proposed that the superordinate construct should tap into different kinds of perceptions of uniquely human mental states: the perception of free will, cognition, moral virtue, intentions and capacity for conscious emotion. Furthermore, it should also conceptually tap into the analogous perception of a brand as a human-like entity through dimensions such as appearance and personality.

According to Law, Wong and Mobley (1998, p.747), "under the latent model the overall latent construct leads to various dimensions of the construct, because the dimensions are simply different ways the construct is realized". In line with this, dimensions were viewed as different facets that are specific manifestations of the overall construct (Edwards, 2001). In order to justify representations of the dimensions as a specific manifestation of the overall construct, Law et al. (1998) suggested that because commonality among the dimensions is a defining aspect of the latent models, there should be evidence of moderate inter-correlations among the dimensions. There should also be evidence for construct clarity of the lower-level dimensions to ensure the unique contribution of these dimensions to the latent construct. Since, to the best of our knowledge, our study is the first to test the multidimensional structure of brand anthropomorphism, we have avoided speculating about a specific number of final dimensions.

\subsection{Existing measures of brand anthropomorphism}

The nature of the higher-order structure and multidimensionality of brand anthropomorphism has not been explored systematically, and thus no reliable measure of brand anthropomorphism has emerged. As previously mentioned, within the marketing stream of research, a few measures of brand anthropomorphism have been used as manipulation checks, with the measures often containing items adopted from scales that have emerged from other fields (Waytz, Cacioppo, et al., 2010; Waytz, Gray, et al., 2010). While those brand anthropomorphism measures exhibit some internal consistency as indicated by the acceptable levels of Cronbach's $\alpha$, there is no further evidence to support their psychometric properties such as their convergent and discriminant validity.

Waytz, Cacioppo, et al. (2010) developed individual differences in an anthropomorphism questionnaire (IDAQ) to measure people's tendency to anthropomorphise across an array of non-human agents. The items reflect mental state attribution (the extent to which a non-human agent has "a mind of its own," "consciousness," "intentions," "free will," and "can experience emotions") and capture two dimensions - anthropomorphism of animal stimuli and anthropomorphism of non-animal stimuli. The authors concluded that these two dimensions are manifestations of a more general tendency to anthropomorphise non-human agents. Although the whole scale has been rarely used to assess brand anthropomorphism, research on product and brand anthropomorphism often adopt the items employed in the scale. This practice warrants some precaution because the original measure was not developed and tested in relation to brands. Because there is no insight into discriminant and nomological validity in relation to brand constructs, the scale's applicability in capturing brand and marketing phenomena is limited. Furthermore, because the purpose of the IDAQ was to capture the tendency to anthropomorphise various non-human agents, the scale's dimensions emphasise commonly anthropomorphised agents. This suggests that a more precise factor structure is necessary for the scale that intends to measure the specific phenomenon of brand anthropomorphism. In 
Study 5 we provide empirical evidence that demonstrates that the BASC is superior in capturing brand anthropomorphism than the measure that adopts items from IDAQ.

Guido and Peluso (2015) developed a scale to capture the anthropomorphic perception of products. While the scale exhibits satisfactory psychometric properties, it is limited by the product domain and the subsequent arguments explain why it would be problematic to adopt this scale for measuring the anthropomorphism of brands. The scale measures the external aspect of product anthropomorphism that consumers infer by using the visual information of the product. As mentioned in the introduction, the majority of the items are highly specific in capturing the extent to which a product is visually similar to human physiognomy. Hence, they are limited in their capacity to capture other indicators of analogical brand anthropomorphism. Moreover, the scale does not measure the attribution of distinct human mental states, which is considered to be an essential aspect of anthropomorphism (Epley et al., 2007), and therefore the scale does not fully qualify to measure brand anthropomorphism.

\section{Study 1: Content validity and latent structure}

The objectives of this study were to (1) generate a set of items that would constitute the dimensions of anthropomorphism identified in the literature, (2) provide evidence of content validity, and (3) test the factorial composition of the generated items by using an exploratory factor analysis (EFA). We performed an EFA in order to minimise the misspecification of the number of factors and maximise convergent and discriminant validity of the items constituting each factor.

\subsection{Item generation and content validation}

Following the recommendations from previous scale development research (DeVellis, 2003), a broad set of items was generated to capture the potential aspects of brand anthropomorphism. The content specifications were developed based on (1) a comprehensive literature review on anthropomorphism, mind attribution, dehumanisation and human uniqueness, and (2) existing measures of anthropomorphism across the fields. Based on this, seven initial domains were identified which were deemed appropriate as facets of the construct: intentions, cognition, moral virtue, free will, personality, appearance, and conscious emotionality.

The initial pool consisted of 68 items, which were produced on the basis of the relevant literature used for the domains' specifications. Next, the items were evaluated by five independent judges from the management school. Adopting the procedure suggested by Obermiller and Spangenberg (2000), the judges were given a definition of brand anthropomorphism and were asked to rate the extent to which each item represents the construct - "very good", "good", "fair" or "poor". The judges were also asked to provide additional comments on the items' ambiguity, clarity and redundancy. The items were retained if they were rated as "very good" or "good" in representing the construct by a majority of the judges. This process eliminated 24 items, resulting in a set of 44 items. On the basis of the provided comments, the items' wording was further revised (DeVellis, 2003). The items were evaluated for a second time by three additional independent marketing experts using the same procedure. They confirmed the adequacy of the remaining 44 items.

\subsection{Stimulus development}

The brands used in Study 1 and 2 are fictitious mineral water brands in which brand anthropomorphism was manipulated (see Figure 1). Fictitious brands were used to limit the effect of possible existing brand associations and perceptions that might introduce a source of variation in the results. We used two conditions (anthropomorphised vs. non-anthropomorphised) for an additional assessment of content validity of the scale. Specifically, by performing a known-group comparison, we aimed to establish known-group validity, which is used to assess whether the measure could produce results for a group of people who are likely to score high or low on the developed scale (MacKenzie, Podsakoff, \& Podsakoff, 2011). Brand anthropomorphism is often manipulated in experimental designs, and thus establishing known-group validity not only provides support for the scale's usefulness and validity, but it also provides additional support for the appropriateness of using anthropomorphism manipulations, as discussed below. 
Two different versions of advertisements (anthropomorphised vs. non-anthropomorphised) were custom-designed, with the only difference between the versions being the extent of humanisation through visual and verbal cues (see Figure 1). To maximise the likelihood of activating human schema and subsequently, the perception of a brand as a human-like entity, the following strategies were used. Firstly, the brand package was anthropomorphised using an hourglass-shaped bottle (vs. rectangle-shaped), as previous research has documented that observing a package shaped like a human body activates human knowledge (De Bondt, Van Kerckhove, \& Geuens, 2018). Similarly, through visual cues the anthropomorphised brand was portrayed as engaging in human behaviour (Puzakova et al., 2013). Secondly, following previous work (Aggarwal \& McGill, 2007), brand anthropomorphism was manipulated using verbal cues by employing first-person (vs. third-person) communication styles. Finally, to further foster the perception of a brand image as a real person through verbal cues, the brand in the anthropomorphised condition was named Aquina (vs. Water+).

To validate the anthropomorphism manipulations, we conducted a pre-test with 13 independent judges from the management school. The concept of brand anthropomorphism was explained to the judges. After that they were presented with both non-anthropomorphised and anthropomorphised stimuli. Next, they were asked to choose the brand that they perceived as more anthropomorphic. For each stimulus, the responses were coded as "not chosen" (0) or "chosen" (1). All judges chose the anthropomorphised brand. An exact McNemar's test demonstrated that the proportion of responses was statistically different, $p<.001$, further indicating that the conditions were perceived differently.

\subsection{Participants and procedure}

Following previous studies (Tinsley \& Tinsley, 1987; Worthington \& Whittaker, 2006), the sample size of at least 300 participants was determined a priori to ensure stable patterns of covariation during the EFA. Across all studies, we used participants from the general population in order to provide external validity, factor structure stability, and generalizability for the findings (Jackson, Gillaspy, \& Purc-Stephenson, 2009; Wells, 1993).

We recruited 393 adults in the United Kingdom (65.9\% females, median age 35) from the online crowdsourcing platform Prolific Academic (Peer, Brandimarte, Samat, \& Acquisti, 2017) in exchange for a nominal payment. Participants were randomly presented with one of two (i.e., anthropomorphised vs. non-anthropomorphised) versions of brand advertisement. They then rated the brands on 44 potential scale items (e.g., "This brand appears lifelike", "This brand has beliefs of its own" and "This brand can experience compassion for people who feel down") from "strongly disagree" (1) to "strongly agree" (7) in addition to answering demographic questions. In the subsequent Prolific Academic studies, we used pre-screening criteria to screen the participants from the previous studies.

\subsection{Results}

The factorability of the data prior to conducting an EFA was assessed using Kaiser-Meyer-Olkin (KMO) measure of sampling adequacy and Bartlett's test of sphericity. Bartlett's chi-square was significant $\left(\chi^{2}(946)=22273.13, p<\right.$ $.001)$ and $\mathrm{KMO}$ exceeded the recommended value of .60 (KMO=.97; Tabachnick \& Fidell, 2012), indicating that factor analysis can be applied to the data.

An EFA was performed using principal axis factoring and Promax rotation allowing the inter-factor correlations. The initial EFA revealed five factors with eigenvalues greater than 1. Inspection of scree-plot suggested the extraction of fewer factors. Using the cut-off criteria of .60 (e.g., Russell, Norman, \& Heckler, 2004) for a factor loading and .32 for the cross-loadings (Tabachnick \& Fidell, 2012), the items were removed on a one-by-one basis. The changes in the factorial solution were examined following the item removal. The item-removal procedure resulted in an interpretable four-factorial solution consisting of 26 items. Further inspection of the scree-plot confirmed the extraction of four factors. The factors were labelled as appearance, moral virtue, conscious emotionality and cognitive experience.

These four dimensions are different manifestations of the extent to which consumers perceive a brand as a humanlike entity. Appearance refers to perception of superficial human-like characteristics such as morphological similarities, while the three other factors tap into three kinds of mental state perceptions. Specifically, the moral virtue dimension measures the inclination of consumers to perceive a brand as a moral entity. Cognitive experience refers to the perception of a brand as capable of engaging in different cognitive tasks (e.g., exhibiting free will, thinking and reasoning). Finally, the conscious emotionality dimension measures the perception of a brand as capable of experiencing cognitively complex emotions, such as shame and guilt. 


\section{Study 2: Scale refinement, purification and validation}

The objectives of this study were to (1) validate the suitability of the factor structure of the BASC, (2) further refine the scale, (3) establish convergent and discriminant validity at the dimensional level, (4) assess a higher-order model of the BASC, and (5) establish known-group validity of the scale.

\subsection{Sample and procedure}

Following recommendations proposed by Worthington and Whittaker (2006), a minimum sample size of 100 participants and at least 5 participants per parameter was determined a priori to ensure stable parameter estimates during a confirmatory factor analysis (CFA). This criterion was used in Study 2 to Study 5 to provide evidence of the stability of the factor structure, by using CFA across four independent samples. A new sample of 403 adults in the United Kingdom (65\% females, median age 35) was recruited through Prolific Academic to participate in an online study in exchange for payment. Participants were randomly assigned to one of the stimuli used in Study 1 . Next, they rated the brand on the 26 BASC items from "strongly disagree" (1) to "strongly agree" (7), in addition to answering demographic questions.

\subsection{Results}

Results of the CFA for the correlated model consisting of four dimensions with 26 items, derived from the EFA, indicated an acceptable fit for the model (CFI =.93; TLI =.92; IFI =.93; RMSEA =.096; SRMR =.041). For the comparative fit index (CFI) and non-normed fit index (TLI and IFI), values above 0.90 indicate "acceptable" fit and values above .95 are considered as "good", and SRMR values below .08 are considered acceptable (Hu \& Bentler, 1999). The traditional .05 cut-off value for RMSEA has been questioned (Steiger, 2000) and is considered to be less preferable for models with small or moderate sample sizes because it might lead to over rejection of appropriate models (Hu \& Bentler, 1999). Because there is no single conclusive test of significance of the model fit (Hu \& Bentler, 1999), throughout the study we evaluated the overall model fit based on the combination of the reported fit indices.

The obtained fit statistics suggested that further improvements for the scale were possible. As such, we inspected the modification indices. Following previous research (Böttger, Rudolph, Evanschitzky, \& Pfrang, 2017), items were identified for exclusion when one or both of two possible results occurred: (1) the item accounted for a single high modification index (>30) and/or (2) the item was involved in ten or more significant modification indices (> 3.84). Based on these criteria, six items including "This brand reflects on its own behaviour" and "This brand is capable of acting freely regardless of external constrains", were eliminated. The remaining 20 items ("appearance"4 items; "moral virtue"- 3 items; "cognitive experience"- 7 items; "conscious emotionality"- 6 items) were subjected to a CFA, which produced an improved model fit (CFI= .97; TLI= .97; IFI = .97; RMSEA= .069; SRMR= .037).

To achieve a more parsimonious scale, four items each with the highest indicator reliabilities in "conscious emotionality" and "cognitive experience" dimensions, were selected (e.g., Homburg, Schwemmle, \& Kuehnl, 2015). Next, to reduce the number of items further and minimise redundancy, three independent judges closely examined the remaining 15 items for similarities, ambiguity and clarity. They omitted two items based on similarity between other items in their related sub-scales (one item from the "appearance" dimension and one from the "cognitive experience" dimension). For instance, the judges omitted the item "Some of the features of this brand resemble a human" as it was highly similar to the rest of the items in the appearance dimension. Psychometrically, this 13-item correlated model produced a good fit (CFI= .99; $\mathrm{TLI}=.98$; IFI=.99; RMSEA= .058; SRMR=.032). See Table 1 for the factor loadings of the 13 items that were retained during this study.

\subsection{Construct validation}

Convergent validity of the 13-item BASC at the dimensional level was assessed using the following criteria: (1) all items should load highly and significantly on their hypothesised factors with factor loadings above .40 (DeVellis, 2003), (2) the composite reliability (CR), a measure for internal consistency reliability, for each construct should be above .70 (Nunnally \& Bernstein, 1994), and (3) the average variance extracted (AVE) for each construct should be above .50 (Fornell \& Larcker, 1981). As shown in Table 1, all hypothesised factor loadings were statistically significant and reasonably large, ranging from .78 to .96 . The CRs exceeded the required threshold of .60, indicating that the items were sufficient in representing their hypothesised constructs. The AVEs for each construct were well above 
the required threshold of .50, demonstrating that a large amount of variance was captured by each construct, rather than being due to a measurement error. Taken together, these results indicated strong convergent validity.

\section{INSERT TABLE 1 ABOUT HERE}

The discriminant validity was assessed using the Fornell-Larcker criterion and the Heterotrait-Monotrait (HTMT) criterion. Following the Fornell-Larcker criterion, the square root of AVE for each construct was required to be greater than the correlation between the respective constructs (Fornell \& Larcker, 1981). Table 1 shows that this criterion was met for all constructs. Secondly, the discriminant validity was established using HTMT (Henseler, Ringle, \& Sarstedt, 2015). The acceptable ratios for each pair of constructs should be <.90 (Henseler et al., 2015). Table 1 shows that the ratios were below .90, suggesting discriminant validity between the constructs. In addition, the HTMT inference using the bootstrap method was calculated to check whether HTMT was significantly different from the value one. The confidence intervals did not contain the value one, indicating the distinctiveness of the dimensions (Henseler et al., 2015). The overall results provided sufficient evidence for discriminant validity among the scale's dimensions.

Alternative models were compared to evaluate the dimensionality of the BASC. The four-factorial model was contrasted with alternative models consisting of a model in which all items loaded on the single factor and the series of models, combining different pairs of the constructs. The model comparison was based on overall model fit, confirmatory fit indices differences ( $\Delta \mathrm{CFI}$; Widaman, 1985$)$ and Akaike information criterion differences $\left(\Delta_{i} ;\right.$ Burnham \& Anderson, 2004). The more constrained model is more appropriate when $\Delta C F I$ is less than .01 (Cheung \& Rensvold, 2002), $\Delta_{i}$ is lower than or equal to 2 (Burnham \& Anderson, 2004), and the constrained model exhibits superior fit based on various indices in comparison to the baseline model. As can be seen in Table 2, the single factor model fitted the data poorly (CFI =.66; $\mathrm{TLI}=.59 ; \mathrm{IFI}=.66 \mathrm{RMSEA}=.29 ; \mathrm{SRMR}=.15)$, supporting the multidimensional nature of the construct. Furthermore, the four-factorial model achieved a significantly better fit with respect to various fit indices. The $\triangle C F I$ values for alternative models were greater than .01, indicating that the baseline model represented the data more appropriately. Large $\Delta_{i}$ between the baseline model and alternative models provided additional support favouring the four-factorial model. Overall results offer sufficient evidence for the dimensionality of the model consisting of four factors.

\section{INSERT TABLE 2 ABOUT HERE}

\subsection{Validation of the higher order BASC}

Because brand anthropomorphism has been viewed as a superordinate construct explained by a number of related dimensions, a higher order model was subjected to a CFA in which the overall construct of brand anthropomorphism was represented as the second-order factor. This conceptualisation was initially supported because interfactor correlations were significant and moderate in size (see Table 1), suggesting that the construct was best conceptualised as a second-order construct (Chen, Sousa, \& West, 2005; Law, Wong, \& Mobley, 1998). Furthermore, a second-order factorial structure is generally preferable in situations where both first- and second-order factorial models fit data equally well, as it allows the co-variation among first-order factors by accounting for corrected errors which are common within the first-order factorial models (Gerbing \& Anderson, 1984). Finally, it is not the constitutive dimensions of brand anthropomorphism, but rather, the higher-order construct that has been of interest in the testing of marketing and consumer behaviour theories.

The second-order factor analysis supported the conceptualisation that the constitutive dimensions were linked to a common higher-order construct ( $\mathrm{CFI}=.99 ; \mathrm{TLI}=.98$; IFI =.99, RMSEA =.057; SRMR =.035). The second-order model fitted the data equally well as the first-order model. Convergent validity for the second-order model was assessed by examining factor loadings and computing composite latent variable reliability (CLVR; El Akremi, Gond, Swaen, De Roeck, \& Igalens, 2018) and AVE (MacKenzie et al., 2011). As shown in Table 3, the values (CLVR = .85; $A V E=.61$ ) were above the recommended thresholds, supporting convergent validity and internal consistency of the higher-order construct. In addition, all second-order factor loadings were statistically significant at the .001 level and substantial in size, ranging from .52 to $.90(M=.75)$ 


\section{INSERT TABLE 3 ABOUT HERE}

\subsection{Known-group validity}

Known-group validity is used to assess the content validity of a scale by demonstrating that the output of the scale systematically varies, based upon known performance of the construct that the scale is intended to measure (MacKenzie et al., 2011). We performed a known-group comparison between the two conditions used in the study, as they were a priori expected to differ with respect to brand anthropomorphism. We anticipated that the "anthropomorphised" condition would significantly differ from the "non-anthropomorphised" condition. Supporting these expectations, in the "anthropomorphised" condition, participants scored significantly higher than those in the "nonanthropomorphised" condition on the overall BASC $\left(M_{\text {ANTH }}=4.07, M_{\text {NON-ANTH }}=3.07 ; t(401)=8.13, p<.001\right)$. Hence, we concluded that the BASC exhibits known-group validity and the manipulation of brand anthropomorphism was successful, providing additional support for the appropriateness of the employed manipulations.

\section{Study 3: Scale purification and measurement invariance}

The objectives of this study were to (1) confirm applicability of the BASC using the existing brands and if necessary, perform further refinement at the items level, and (2) provide evidence for measurement invariance.

\subsection{Sample, procedure and measures}

A new sample of 320 adults in the United Kingdom (65\% females, median age 30) was recruited through Prolific Academic to participate in an online study in exchange for payment. Participants were randomly assigned with one of 15 popular brands (Amazon, Apple, Dove, Facebook, Google, IBM, Innocent, John Lewis, Lush, M\&S, Nestle, Nike, Pret a Manger, Tesla, and Virgin). They then indicated their familiarity with the assigned brand and responded to the measure of brand anthropomorphism from "strongly disagree" (1) to "strongly agree" (7) in addition to answering demographic questions. In relation to brand familiarity, we found that the tests throughout validation studies were robust across different levels of familiarity (see Web Appendix). Therefore, in this and subsequent studies, we used a full sample.

\subsection{Results}

Before testing the higher-order model of the BASC, the four-factor correlated model was subjected to a CFA to examine inter-factor correlations and whether additional scale purification at the item level was necessary. The model produced an acceptable overall fit (CFI =.95; $\mathrm{TLI}=.94 ; \mathrm{IFI}=.95, \mathrm{RMSEA}=.10 ; \mathrm{SRMR}=.066)$. On the basis of the CFA, one item was removed from the "conscious emotionality" factor because of its relatively low factor loading and squared multiple correlation, and relatively high modification index (e.g., Vandecasteele \& Geuens, 2010). Following the item's removal, the model produced an improved overall fit (CFI =.96; TLI =.95; IFI =.96, RMSEA =.094; SRMR =.057). Supporting convergent validity at the first-order level, all factors had reasonably high item loadings, CRs and AVEs (see Table 3). Web Appendix provides detailed results for discriminant validity and dimensionality of the scale. In summary, the Fornell-Larcker criterion and HTMT criterion were met for every pair of constructs. The model comparison demonstrated that the four-factorial model was superior to the alternative models, supporting the distinctiveness of the dimensions.

The factors were positively and highly correlated (correlation coefficients range from .42 to .70, p's $<.001$; see Web Appendix), issuing further evidence for a higher-order conceptualisation. The final second-order 12-item BASC depicted in Figure 2 produced a good fit (CFI =.96; TLI =.95; IFI =.96, RMSEA =.092; SRMR =.058). All second-order loadings were statistically significant and reasonably substantial in size, ranging from .54 to $84(M=.73)$. The model exhibited good convergent validity (CLVR =.82 and AVE =.54). As shown in Table 3, across previous, current and future validation studies, the proposed four-factorial second-order BASC model exhibited strong convergent validity and consistently fits the data as well as the first-order model, thus confirming the treatment of brand anthropomorphism as a higher-order construct. 


\subsection{Test for measurement invariance}

The measurement invariance test contributes to the evaluation of the overall construct validity of the scale by indicating the extent to which the scale operates equivalently across different groups and holds the same meaning for members of these groups (Vandenberg \& Lance, 2000). Establishing invariance is important to ensure the meaningful and unambiguous interpretation of future group-based comparisons. Following Vandenberg and Lance (2000), we used gender to investigate the extent to which individuals across two groups (females vs. males) respond to the scale in similar ways. Gender was chosen because it is a common segmentation variable in different marketing contexts (for a review see Meyers-Levy \& Loken, 2015) and is often used in testing measurement invariance (Chen, Sousa, \& West, 2005). In addition, as gender is a defining consumer characteristic, not supporting the measurement invariance would require additional data collection or engagement in strategies aimed at reducing the difference.

Following the procedure recommended by Chen et al. (2005), a hierarchical series of nested models (see Table 4) were tested to determine whether the second order-factor structure of the BASC was statistically equivalent across the two groups. The models were analysed via chi-square difference test (Bentler \& Bonett, 1980). However, as $\chi^{2}$ statistic is sensitive to the sample size, the assessment of the models was performed by examining $\Delta C F I$ according to the recommendations of Cheung \& Rensvold (2002).

\section{INSERT TABLE 4 ABOUT HERE.}

In support of configural invariance, an unconstrained second-order model across the two groups (female vs. males) demonstrated a good fit ( $\mathrm{CFI}=.96 ; \mathrm{TLI}=.95 ; \mathrm{IFI}=.96$, RMSEA =.067; SRMR =.058). All items loaded on their hypothesised factors, with reasonably large $(>.70)$ and statistically significant $(p<.001)$ loadings for both groups. As can be seen from Table 4, the chi-square difference test was not significant for Model $2\left(\Delta \chi^{2}[8]=3.76, n s\right.$. $)$, Model $3\left(\Delta \chi^{2}[3]=1.09, n s\right)$, Model $4\left(\Delta \chi^{2}[8]=7.51, n s\right)$, and Model $5\left(\Delta \chi^{2}[4]=7.46, n s\right)$, and the values for $\Delta C F I$ between these models were $\leq .01$, indicating that the first-order factor loadings, second-order factor loadings, measurement intercepts and intercepts of first-order factors were invariant across female and male groups respectively.

Although, the chi-square difference test between Model 6 and Model 5 was significant $\left(\Delta \chi^{2}[4]=9.67, p=.05\right)$, $\Delta$ CFI between the models was $\leq .01$, thus supporting invariance in the disturbances between females and males. The chi-square difference test between Model 7 and Model 6 was significant $\left(\Delta \chi^{2}[12]=23.22, p=.03\right)$. However, given that there was no substantial difference in CFI (.96 vs. .96), we concluded that invariance of measurement residuals was supported. Taken together, the results provide substantial support for measurement invariance of the BASC.

\section{Study 4: Discriminant validity}

The aim of this study was to provide evidence of discriminant validity of the BASC in relation to conceptually relevant constructs such as brand attitude, brand affect, brand loyalty and self- brand connection, by demonstrating that brand anthropomorphism is a distinct construct and not just an empirical reflection of other related brand constructs (Voorhees, Brady, Calantone, \& Ramirez, 2016).

Brand anthropomorphism is related yet distinct from brand attitudes and brand affect. Brand attitude reflects consumers' overall evaluations involving the extent to which consumers favour or disfavour a brand (Keller, 1993). In this, brand is judged based on the attributes that consumers consider desirable. Although both brand attitude and brand anthropomorphism involve evaluation of a brand, brand anthropomorphism is indicative of the perception of brand humanness, which can be processed as a desirable attribute, subsequently shaping attitudes towards the brand (e.g., Aggarwal \& McGill, 2007). Sharing some theoretical grounds with brand attitude, brand affect refers to subjective, emotional aspects of consumers' overall evaluations. Chaudhuri and Holbrook (2001) define brand affect as "a brand's potential to elicit a positive emotional response in the average consumer as a result of its use" (p.82). Although perceiving a brand as a human-like entity might evoke positive emotional response (Landwehr et al., 2011), brand anthropomorphism does not capture the strength of the development of emotional ties between the consumer and a brand.

Conceptually, brand loyalty integrates both behavioural loyalty, i.e., repetitive purchases and attitudinal loyalty, i.e., favourable evaluations toward the brand (Watson, Beck, Henderson, \& Palmatier, 2015). As discussed previously, brand anthropomorphism can be viewed as a favourable brand attribute that shapes positive evaluations, 
contributing to attitudinal loyalty. Moreover, brand anthropomorphism is related to the concept of brand loyalty, in the sense that humanizing a brand might also encourage a behavioural response in which replacement for a product will be done with another exemplar from the anthropomorphised brand (Chandler \& Schwarz, 2010). From the conceptual point of view, brand anthropomorphism assesses the magnitude of the perception of a brand in human-like terms and does not capture behavioural responses and is thus distinct from brand loyalty.

Brand anthropomorphism is related to, but distinct from self-brand connection. Self-brand connection is conceptualised as the extent to which consumers have incorporated a brand into their self-concept (Escalas \& Bettman, 2005). When the consumers' image closely overlaps with the brand image, a strong self-brand connection is likely to emerge. Brand image consists of unique and favourable brand associations and involves such aspects as user imagery and psychological benefits (Keller, 1993). In this, perceiving a brand in human-like terms can create a favourable and unique association, which then can contribute to an overlap between brand image and the consumer's self-concept. However, brand anthropomorphism does not involve assessment of the strength of the connection between the consumer's self-concept and brand image. Furthermore, brand anthropomorphism does not necessarily connect the consumer's self to the brand.

\subsection{Sample, procedure and measures}

A sample of 334 adults in the United Kingdom (63.2\% females, median age 29) recruited through Prolific Academic participated in an online study in exchange for payment. Participants were randomly assigned with one of 15 brands from Study 3. They then indicated their familiarity with the assigned brand and responded to the BASC and measures of brand attitude (Spears \& Singh, 2004), brand self-connection (Escalas \& Bettman, 2005), brand affect (Chaudhuri \& Holbrook, 2001) and brand loyalty (Yoo \& Donthu, 2001). Participants indicated the degree to which they agreed or disagreed with each statement along a 7-point scale (1=strongly disagree; 7=strongly agree).

\subsection{Results}

As shown in Table 5, all measures exhibited satisfactory convergent validity as indicated by their CRs and AVEs. Discriminant validity between the constructs was established using the Fornell-Larcker criterion and the HTMT criterion. As reported in Table 5, the square root of AVE for the BASC was greater than the correlations with other brand constructs, providing support for discriminant validity of the BASC (Fornell \& Larcker, 1981). The HTMT ratios between brand anthropomorphism and other constructs ranged from .30 to .60 , well below the threshold of .90 (Henseler et al., 2015). Overall, these results provide sufficient evidence of the discriminant validity of the BASC. In line with the preceding discussion, results demonstrate that brand anthropomorphism is related to, but distinct from, overall brand evaluation (brand attitude), emotional brand evaluation (brand affect), behavioral response (brand loyalty) and self-concept overlaps and integration (self-brand connection).

\section{INSERT TABLE 5 ABOUT HERE}

\section{Study 5: Predictive and incremental validity}

The results show that the BASC exhibits high levels of convergent and discriminant validity. However, in order to be applicable in research and practice, the measure should be capable of predicting some theoretical outcomes. For this reason, we proposed a set of relationships regarding how perceiving a brand as a humanlike entity affects consumers' brand commitment and brand trust. Furthermore, we assessed the incremental validity of the BASC by exploring its ability to predict these outcomes above and beyond the brand-adopted measure of anthropomorphism (labelled here as the BAMA). We used the BAMA as a proxy measure to demonstrate that the BASC is superior to the commonly utilised method of brand anthropomorphism assessment in which measures adopt items similar to those in the IDAQ (Waytz, Cacioppo, et al., 2010).

Brand commitment is conceptualised as an affective construct and defined as a desire to maintain relationships with the brand (Allen \& Meyer, 1990). Affective commitment comes from a holistic judgement of a brand in terms of liking, similarity, shared values, attachment and identification with this brand (Fullerton, 2003). Because consumers tend to form various relationships with the brands they anthropomorphise (Aggarwal \& McGill, 2012; Kim \& Kramer, 2015), it is plausible to argue that they would express an enduring desire to maintain those relationships (Moorman, Zaltman, \& Deshpande, 1992). Further support for this argument comes from research which has 
demonstrated that when the object is thought about in humanised terms, consumers are less willing to replace it (Chandler \& Schwarz, 2010). This can be linked to the greater liking, attachment and connectedness to entities perceived as human-like (Chandler \& Schwarz, 2010; Tam et al., 2013). Therefore, as consumers' perception of the brand as a human-like entity increases, consumers are more likely to experience the psychological state of commitment.

Brand trust can be conceptualised as "the willingness of the average consumer to rely on the ability of the brand to perform its stated function" (Chaudhuri \& Holbrook, 2001, p.81). The literature generally supports the notion that trust is associated with beliefs such as competence and a sense of security (Delgado-Ballester \& Luis MunueraAlemán, 2001). During the consumption process, consumers often experience vulnerability from the actions and decisions of the brand, and trust in the latter is based on the belief that it would not harm the consumers by taking opportunistic advantages of their vulnerability (Delgado-Ballester \& Luis Munuera-Alemán, 2001; McKnight \& Chervany, 2001). According to McKnight and Chervany (2001), people often trust others because of their cognitive perception of the trustee's attributes or characteristics. In order to behaviourally trust someone, a person should perceive these characteristics as beneficial to the self, meaning that they are willing and capable of acting in his/her interest. In line with this, recent research on impression formation shows that the information about the morality of the target is essential in establishing whether it is beneficial or harmful to the self (Brambilla, Carraro, Castelli, \& Sacchi, 2019) because people often need to know whether someone's intentions or actions are beneficial or harmful and therefore, agents who lack moral qualities are perceived as possessing greater levels of threat (Brambilla, Sacchi, Rusconi, Cherubini, \& Yzerbyt, 2012). Building on these findings, we argue that when a brand is perceived as a human-like entity with the capability for moral virtue, thinking and emotions, consumers feel more secure and certain that the brand would not harm them.

\subsection{Sample, procedure and measures}

The sample consisted of 146 adults from the United Kingdom (61.4\% females, median age 30) who were recruited through Prolific Academic to participate in an online study in exchange for payment. Participants were randomly assigned with one of ten popular brands (Adidas, Cadbury, Colgate, Heinz, Kit-Kat, Lego, Nintendo, Nissan, The Body Shop, and Timberland). They indicated their familiarity with the assigned brand and then rated the brand on the measures of brand anthropomorphism, brand trust (Chaudhuri \& Holbrook, 2001) and brand commitment (Eisingerich \& Rubera, 2010). The participants indicated the degree to which they agreed or disagreed with each statement along a 7-point scale (1=strongly disagree; $7=$ strongly agree).

\subsection{Results}

The measures exhibited good convergent validity (see Web Appendix). The predictive validity of the BASC with the BAMA was compared by testing two hierarchical regression models, using brand commitment and brand trust as dependent variables. In the first step, the BAMA was entered as an independent variable in the models. As shown in Table 6 , the BAMA was a significant predictor of brand commitment $(\beta=.33, p<.001)$ and brand trust $(\beta=.37, p$ $<.001$ ), with $R^{2}$ of .10 and .14 respectively. In the second step, the BASC was added to the models. The BASC significantly predicted brand commitment $(\beta=.39, p=.001)$ and brand trust $(\beta=.57, p<.001)$ above and beyond that of the BAMA, as demonstrated by the significant change in $R^{2}\left(p^{\prime} s \leq .001\right)$. In both models, the magnitude of the standardised coefficients of the BASC was larger than that of the BAMA, supporting its unique and superior effect on the dependent variables. Taken together, these results issued evidence for the predictive and incremental validity of the BASC.

\section{INSERT TABLE 6 ABOUT HERE}

\section{Study 6: Test-retest reliability}

To assess the scale test-retest reliability and the construct temporal stability, responses for the BASC were collected on two occasions separated by a week, from a new sample of 70 British adults (67.1\% females, median age 31) recruited through Prolific Academic. The sample size was specified based on from previous scale development research that employed the assessment of test-retest reliability (e.g., Tett, Fox, \& Wang, 2005; Tu, Khare, \& Zhang, 2012). Adopting a procedure by Brakus, Schmitt and Zarantonello (2009), the respondents were asked to rate one 
of two well-known brands in the UK (Waterstones and Philips) on the 12-items BASC. A week later the same participants were asked to rate the two brands again. The second administration was completed by 65 respondents.

In order to examine the BASC's test-retest reliability, we correlated the responses provided by participants on the two measurement occasions. The test-retest reliability was evidential by the substantial and statistically significant correlation between administration points $(r=.76, p<.001)$. This level of test-retest correlation is comparable to those reported in other studies. For example, Reich, Beck, and Price (2018) reported test-retest correlation of .78 for their preference for local foods scale, conducted six days apart. We also performed a paired sample t-test to investigate the extent to which BASC score changes across time. The result of the paired t-test revealed that the scores did not significantly differ across the two measurement points. Based on the overall results, we concluded that the BASC exhibits reasonably good temporal reliability.

\section{General Discussion}

Marketing practitioners often persuade consumers to view brands as if they were real humans by imbuing their brands with human-like qualities. Prior research generally supports the assertion that if consumers anthropomorphise a brand, and thus consider the brand as having important human-like qualities, it creates positive branding outcomes such as favourable consumers attitudes (Aggarwal \& McGill, 2007; Landwehr et al., 2011) and lower willingness to replace the anthropomorphised entity (Chandler \& Schwarz, 2010). In interpersonal settings, Chen et al., (2017) found that following situations that threaten interpersonal connection, consumers exhibit greater preference for anthropomorphised brands due to the need for social affiliation. Similarly, consumers can also partly compensate their social needs by interacting with anthropomorphised products or brands (Mourey, Olson, \& Yoon, 2017). In contrast, some authors investigated the negative aspects of this phenomenon. For instance, Puzakova et al. (2013) demonstrated that brand anthropomorphism negatively affects consumers' attitudes and evaluations towards a brand that has faced negative publicity because of its wrongdoings. Although brand anthropomorphism has attracted considerable attention and recognition from both researchers and practitioners, previous research is largely silent on how the construct should be conceptualised and operationalized, resulting in the absence of a valid measure of the construct. In addressing these gaps, the primary aim of this research was to develop and test a reliable and valid measure of brand anthropomorphism.

The higher-order scale to measure brand anthropomorphism (BASC) was developed and validated based on theoretical grounds that reconcile existing perspectives on anthropomorphism. The theoretical definition is reflected by the final set of the scale's dimensions - appearance, moral virtue, cognitive experience and conscious emotionality. In line with our conceptualisation of brand anthropomorphism as a superordinate construct, these dimensions were found to be interdependent, indicating that they are manifestations of a higher-order construct of brand anthropomorphism. The fit of the higher-order model was mathematically similar to that of the first-order model across four studies (cf. Table 3). Consistent with this, we suggest that the BASC should be operationalized preferably as a second-order factor model, as it allows for co-variation among first-order factors and is a better predictor of broadly defined constructs (Edwards, 2001; Gerbing \& Anderson, 1984). Such a model would be of particular interest for researchers who are interested in fully capturing the domain of brand anthropomorphism.

Across the studies, the applicability of the BASC was verified by consistently demonstrating adequate psychometric properties for reliability, dimensionality and convergent, discriminant and predictive validity. Our findings from validation studies suggest that brand anthropomorphism is related to relevant brand constructs, but is conceptually different and not just a mere empirical reflection of these constructs. These findings are especially noteworthy as our study is the first to validate and confirm the empirical distinctiveness of brand anthropomorphism from the extensive number of conceptually related constructs. The findings also suggest that the BASC exhibits reasonably good temporal stability. Furthermore, the BASC is invariant across demographic groups and, therefore, respondents perceive the measure as conceptually similar. In addition, the study allows us to conclude that the BASC performs better in terms of measuring brand anthropomorphism beyond the currently utilised assessment method.

Although the studies reported in this paper do not examine nomological validity, we conducted an additional study, not reported in the paper, to examine this issue. Since anthropomorphism is affected by the process that involves the activation of human knowledge at the moment of making inferences about non-human agents (Epley et al., 2007) and self-knowledge is salient, we reasoned that brand self-congruence positively affects brand anthropomorphism. Since anthropomorphism enhances a brand's ability to be an active participant in the consumer-brand 
relationship (Fournier and Alvarez, 2012), it is expected that brand anthropomorphism leads to brand intimacy, brand commitment, brand trust and brand partner quality. Data from 628 British adults were collected through an online study using established scales in the literature. After ruling out CMV, data were analyzed using PLS-SEM. All hypotheses were supported, providing preliminary evidence of nomological validity of the BASC.

\subsection{Managerial implications}

This research has practical relevance for brand and marketing practitioners. As practitioners readily invest in delivering a human-like brand image, they can use this scale as a diagnostic tool, providing valuable insight into the degree to which the brand is perceived as human-like. Because the scale demonstrates adequate convergent, discriminant and predictive validity, marketing practitioners have a valid and reliable measurement instrument that can be employed to evaluate more accurately how consumers perceive their branding actions and adjust their marketing and communication strategies accordingly. A fundamental idea is that anthropomorphised marketing communication campaign can be critical because it enables or attracts audiences to engage and converse freely with the brand characters that have matching anthropomorphic qualities. Thus, BASC is a long-awaited scale for brand marketers.

The empirical findings that brand anthropomorphism positively affects a variety of brand outcomes, including brand trust and brand commitment, suggest that adopting strategies that facilitate the perception of a brand as a humanlike entity may provide positive return on investment. Specifically, brand trust is directly related to brand loyalty, which in turn contributes significantly to market share and brand equity (Delgado-Ballester \& Luis MunueraAlemán, 2001). On the other hand, brand commitment results in the disconfirmation process in which high-commitment consumers seek for ways to systematically discredit and underrate the claims and offerings made by a competitor brand (Raju, Unnava, \& Montgomery, 2009). Accordingly, by facilitating anthropomorphism in their brand positioning and communications, marketing practitioners can enrich consumer-brand interactions and thus gain competitive advantage. The findings of the preliminary study that demonstrate the nomological validity of BASC, discussed in section 8, further underscores this point. Brand anthropomorphism leads to brand intimacy and brand partner quality, which will lead to positive downstream effects, enhancing competitive advantage. Practically, the BASC is highly valuable for evaluating anthropomorphism-based brand marketing/advertising campaign. For example, BASC can help measure the effectiveness of the character exposed in a brand advertising in generating the anthropomorphism level of the brand. Brand managers may use BASC to ascertain the level of anthropomorphism of their brand in comparison to competing brands. Further, they can use the scale to trace and monitor whether and how their brand's anthropomorphism level affects brand performance, such as brand loyalty, brand equity, brand positioning and brand market share. They can also verify dimensions/aspects - such as appearance, moral virtue, cognitive experience, conscious emotionality - that need to be enhanced for a better anthropomorphism score, leading to better brand performance. In short, the BASC is an essential and powerful measure in anthropomorphism-based brand marketing campaigns.

\subsection{Limitations and future research}

As with any empirical study, there are limitations in this research that should be mentioned. While the findings across the studies are encouraging, it should be noted that scale validation is a continuous process, and additional research is necessary to further establish the discriminant, convergent and predictive validity of the BASC with a much broader range of consumers, based on their individual differences and a broader array of brand types. One of the particular limitations is that the study employs a survey format in which all outcome variables were measured simultaneously. This limits the conclusions regarding the causality we are able to draw from the results.

Surprisingly, in this research we did not find support for intentionality and personality dimensions of brand anthropomorphism. During the EFA in Study 1, items relevant to intentionality and moral virtue loaded on the same factor. This is consistent with mind perception theory (Gray et al., 2007) where both intentionality and morality constitute an agency dimension of the mind. However, because of their low factor loadings, the items representing intentionality were dropped during the process of item deletion. This leads us to speculate that moral virtue is a better manifestation of brand anthropomorphism than intentionality. In regard to the personality dimension, one of the plausible explanations is that personality as a mental state might be a weak manifestation of brand anthropomorphism, because of its relatively weak conceptual affiliation with uniquely human characteristics (Haslam, Bain, 
Douge, Lee, \& Bastian, 2005). Further research could examine the extent to which personality and perceived intentionality of the brand constitute the perception of that brand as human-like.

This research has been limited to the participants selected from the United Kingdom. Although the sample was drawn from the general population containing various demographic profiles supporting the generalisability of the study, there is a need for further examination of the factor structure of the BASC across various cultural contexts. Perceiving non-human agents in human-like terms is considered to be a universal phenomenon (Epley et al., 2007; Guthrie, 1993; Haslam et al., 2008) implying that the meaning of brand anthropomorphism should be similar across cultures. However, it is possible that while retaining the same meaning the construct's dimensions and scale items in various markets might differ due to the cultural contexts, cultural distance and nuances of that market. India, for example, is a culture where the concept of God is anthropomorphised. Recently, in India, the emergence of spiritual/religious brands (e.g., Patanjali) has attracted scholarly attention (Sardana, Gupta and Sharma 2018). Given their spiritual aspects and because anthropomorphism of spiritual entities often involves perception of high agency (Gray et al., 2007), anthropomorphising such brands may involve greater attribution of agency manifested through dimensions such as free will, desire and self-control. This issue needs investigation in other cultures which are high on religiosity and spirituality. In emerging consumer cultures (e.g., Bulgaria, Russia and former Soviet states) brands have been introduced relatively recently, hence general brand knowledge and awareness is considered to vary significantly across age cohorts (Strizhakova, Coulter, \& Price, 2008). Thus, one might sample age cohorts within those countries to evaluate the stability of the scale's dimensions and items. Overall, it is important to validate the scale across cultures to promote cross-cultural research on brand anthropomorphism.

Future research might examine potential moderators for relationships found in this study. For example, one might investigate the extent to which an individual has enough cognitive resources (Reavey et al., 2018) as it might affect the likelihood of activating and applying the knowledge about humans to brands (Epley et al., 2007). Previous research has also documented that individual differences such as self-efficacy and cultural orientation can heighten the tendency to anthropomorphise non-human agents (e.g., Waytz, Morewedge, et al., 2010). The extent to which these individual variables introduce variation into the reported relationships might be a fruitful avenue for further research. Alternatively, one might consider deeper examination of possible paths and constructs in the nomological networks using the BASC. For instance, consistent with the idea that perception of moral qualities leads to a lower perception of threat (Brambilla et al., 2012), one might investigate the extent to which perception of threat from a brand can explain the relationship between brand anthropomorphism and brand trust. It is recommended that researchers continue developing more detailed nomological networks for brand anthropomorphism.

In summary, the BASC demonstrates considerable promise for the study of the brand anthropomorphism phenomenon and may serve as the foundation for evidence-based and theory-driven branding and marketing research. 


\section{References}

Aaker, J. L. (1997). Dimensions of Brand Personality. Journal of Marketing Research, 34(3), 347-356. https://doi.org/10.2307/3151897

Aggarwal, P., \& McGill, A. L. (2007). Is That Car Smiling at Me? Schema Congruity as a Basis for Evaluating Anthropomorphized Products. Journal of Consumer Research, 34(4), 468-479. https://doi.org/10.1086/518544

Aggarwal, P., \& McGill, A. L. (2012). When Brands Seem Human, Do Humans Act Like Brands? Automatic Behavioral Priming Effects of Brand Anthropomorphism. Journal of Consumer Research, 39(2), 307-323. https://doi.org/10.1086/662614

Ahn, H.-K., Kim, H. J., \& Aggarwal, P. (2014). Helping Fellow Beings: Anthropomorphized Social Causes and the Role of Anticipatory Guilt. Psychological Science, 25(1), 224-229. https://doi.org/10.1177/0956797613496823

Allen, N. J., \& Meyer, J. P. (1990). The measurement and antecedents of affective, continuance and normative commitment to the organization. Journal of Occupational Psychology, 63(1), 1-18. https://doi.org/10.1111/j.2044-8325.1990.tb00506.x

Alouche, S. (2014). Brands Think Like Customers, But Do They Feel Like Them? Retrieved November 8, 2019, from https://www.brandingmag.com/2014/10/16/brands-think-like-customers-but-do-they-feel-like-them/

Avery, J. (2012). Defending the markers of masculinity: Consumer resistance to brand gender-bending. International Journal of Research in Marketing, 29(4), 322-336. https://doi.org/10.1016/j.ijresmar.2012.04.005

Belan, K. (2013). Is your brand guilt-free? The new perspective is here to stay. Retrieved November 9, 2019, from http://popsop.com/2013/12/is-your-brand-guilt-free-the-new-perspective-is-here-to-stay/

Bentler, P. M., \& Bonett, D. G. (1980). Significance tests and goodness of fit in the analysis of covariance structures. Psychological Bulletin, 88(3), 588-606. https://doi.org/10.1037/0033-2909.88.3.588

Bering, J. M. (2002). The Existential Theory of Mind. Review of General Psychology, 6(1), 3-24. https://doi.org/10.1037/1089-2680.6.1.3

Böttger, T., Rudolph, T., Evanschitzky, H., \& Pfrang, T. (2017). Customer Inspiration: Conceptualization, Scale Development, and Validation. Journal of Marketing, 81(6), 116-131. https://doi.org/10.1509/jm.15.0007

Brakus, J. J., Schmitt, B. H., \& Zarantonello, L. (2009). Brand Experience: What Is It? How Is It Measured? Does It Affect Loyalty? Journal of Marketing, 73(3), 52-68. https://doi.org/10.1509/jmkg.73.3.52

Brambilla, M., Carraro, L., Castelli, L., \& Sacchi, S. (2019). Changing impressions: Moral character dominates impression updating. Journal of Experimental Social Psychology, 82(January), 64-73. https://doi.org/10.1016/j.jesp.2019.01.003

Brambilla, M., Sacchi, S., Rusconi, P., Cherubini, P., \& Yzerbyt, V. Y. (2012). You want to give a good impression? Be honest! Moral traits dominate group impression formation. British Journal of Social Psychology, 51(1), 149166. https://doi.org/10.1111/j.2044-8309.2010.02011.x

Burnham, K. P., \& Anderson, D. R. (2004). Multimodel Inference Understanding AIC and BIC in Model Selection. Sociological Methods \& Research, 33(2), 261-304. https://doi.org/10.1177/0049124104268644

Caruso, E. M., Waytz, A., \& Epley, N. (2010). The intentional mind and the hot hand: Perceiving intentions makes streaks seem likely to continue. Cognition, 116(1), 149-153. https://doi.org/10.1016/j.cognition.2010.04.006

Chandler, J., \& Schwarz, N. (2010). Use does not wear ragged the fabric of friendship: Thinking of objects as alive makes people less willing to replace them. Journal of Consumer Psychology, 20(2), $138-145$. https://doi.org/10.1016/j.jcps.2009.12.008

Chaudhuri, A., \& Holbrook, M. B. (2001). The Chain of Effects from Brand Trust and Brand Affect to Brand Performance: The Role of Brand Loyalty. Journal of Marketing, 65(2), 81-93. https://doi.org/10.1509/jmkg.65.2.81.18255

Chen, F. F., Sousa, K. H., \& West, S. G. (2005). Teacher's Corner: Testing Measurement Invariance of Second-Order Factor Models. Structural Equation Modeling: A Multidisciplinary Journal, 12(3), 471-492. https://doi.org/10.1207/s15328007sem1203_7

Chen, R. P., Wan, E. W., \& Levy, E. (2017). The effect of social exclusion on consumer preference for anthropomorphized brands. Journal of Consumer Psychology, 27(1), 23-34. https://doi.org/10.1016/j.jcps.2016.05.004

Cheung, G. W., \& Rensvold, R. B. (2002). Evaluating Goodness-of-Fit Indexes for Testing Measurement Invariance. Structural Equation Modeling: A Multidisciplinary Journal, 9(2), $233-255$. 
https://doi.org/10.1207/S15328007SEM0902_5

De Bondt, C., Van Kerckhove, A., \& Geuens, M. (2018). Look at that body! How anthropomorphic package shapes systematically appeal to consumers. International Journal of Advertising, 37(5), 698-717. https://doi.org/10.1080/02650487.2018.1470919

DeGrazia, D. (1997). Great Apes, Dolphins, and the Concept of Personhood. The Southern Journal of Philosophy, 35(3), 301-320. https://doi.org/10.1111/j.2041-6962.1997.tb00839.x

Delgado-Ballester, E., \& Luis Munuera-Alemán, J. (2001). Brand trust in the context of consumer loyalty. European Journal of Marketing, 35(11/12), 1238-1258. https://doi.org/10.1108/EUM0000000006475

Demoulin, S., Leyens, J. P., Paladino, M. P., Rodriguez-Torres, R., Rodriguez-Perez, A., \& Dovidio, J. F. (2004). Dimensions of "uniquely" and "non-uniquely" human emotions. Cognition and Emotion, 18(1), 71-96. https://doi.org/10.1080/02699930244000444

Demoulin, S., Leyens, J., Paladino, M., Rodriguez-Torres, R., Rodriguez-Perez, A., \& Dovidio, J. (2004). Dimensions of "uniquely" and "non-uniquely" human emotions. Cognition \& Emotion, 18(1), 71-96. https://doi.org/10.1080/02699930244000444

Dennett, D. (1988). Conditions of Personhood. In M. F. Goodman (Ed.), What Is a Person? (pp. 145-167). Totowa, NJ: Humana Press. https://doi.org/10.1007/978-1-4612-3950-5_7

DeVellis, R. F. (2003). Scale Development: Theory and Applications. Thousand Oaks, California: SAGE Publications. https://doi.org/10.1038/156278a0

Edwards, J. R. (2001). Multidimensional Constructs in Organizational Behavior Research: An Integrative Analytical Framework. Organizational Research Methods, 4(2), 144-192. https://doi.org/10.1177/109442810142004

Eisingerich, A. B., \& Rubera, G. (2010). Drivers of Brand Commitment: A Cross-National Investigation. Journal of International Marketing, 18(2), 64-79. https://doi.org/10.1509/jimk.18.2.64

El Akremi, A., Gond, J. P., Swaen, V., De Roeck, K., \& Igalens, J. (2018). How Do Employees Perceive Corporate Responsibility? Development and Validation of a Multidimensional Corporate Stakeholder Responsibility Scale. Journal of Management, 44(2), 619-657. https://doi.org/10.1177/0149206315569311

Epley, N., Waytz, A., Akalis, S., \& Cacioppo, J. T. (2008). When We Need A Human: Motivational Determinants of Anthropomorphism. Social Cognition, 26(2), 143-155. https://doi.org/10.1521/soco.2008.26.2.143

Epley, N., Waytz, A., \& Cacioppo, J. T. (2007). On seeing human: A three-factor theory of anthropomorphism. Psychological Review, 114(4), 864-886. https://doi.org/10.1037/0033-295X.114.4.864

Escalas, J. E., \& Bettman, J. R. (2005). Self-Construal, Reference Groups, and Brand Meaning. Journal of Consumer Research, 32(3), 378-389. https://doi.org/10.1086/497549

Fornell, C., \& Larcker, D. F. (1981). Evaluating Structural Equation Models with Unobservable Variables and Measurement Error. Journal of Marketing Research, 18(1), 39. https://doi.org/10.2307/3151312

Fournier, S. (1998). Consumers and Their Brands: Developing Relationship Theory in Consumer Research. Journal of Consumer Research, 24(4), 343-353. https://doi.org/10.1086/209515

Fournier, S., \& Alvarez, C. (2012). Brands as relationship partners: Warmth, competence, and in-between. Journal of Consumer Psychology, 22(2), 177-185. https://doi.org/10.1016/j.jcps.2011.10.003

Fullerton, G. (2003). When Does Commitment Lead to Loyalty? Journal of Service Research, 5(4), 333-344. https://doi.org/10.1177/1094670503005004005

Gerbing, D. W., \& Anderson, J. C. (1984). On the Meaning of within-Factor Correlated Measurement Errors. Journal of Consumer Research, 11(1), 572. https://doi.org/10.1086/208993

Gray, H. M., Gray, K., \& Wegner, D. M. (2007). Dimensions of Mind Perception. Science, 315(5812), 619-619. https://doi.org/10.1126/science.1134475

Gray, K., Waytz, A., \& Young, L. (2012). The Moral Dyad: A Fundamental Template Unifying Moral Judgment. Psychological Inquiry, 23(2), 206-215. https://doi.org/10.1080/1047840X.2012.686247

Guido, G., \& Peluso, A. M. (2015). Brand anthropomorphism: Conceptualization, measurement, and impact on brand personality and loyalty. Journal of Brand Management, 22(1), 1-19. https://doi.org/10.1057/bm.2014.40

Guthrie, S. E. (1993). Faces in the clouds. Oxford, United Kingdom: Oxford University Press.

Haslam, N. (2006). Dehumanization: An Integrative Review. Personality and Social Psychology Review, 10(3), 252264. https://doi.org/10.1207/s15327957pspr1003_4

Haslam, N., Bain, P., Douge, L., Lee, M., \& Bastian, B. (2005). More human than you: Attributing humanness to self and others. Journal of Personality and Social Psychology, 89(6), 937-950. https://doi.org/10.1037/0022- 
3514.89.6.937

Haslam, N., Kashima, Y., Loughnan, S., Shi, J., \& Suitner, C. (2008). Subhuman, Inhuman, and Superhuman: Contrasting Humans with Nonhumans in Three Cultures. Social Cognition, 26(2), 248-258. https://doi.org/10.1521/soco.2008.26.2.248

Haslam, N., \& Loughnan, S. (2014). Dehumanization and Infrahumanization. Annual Review of Psychology, 65(1), 399-423. https://doi.org/10.1146/annurev-psych-010213-115045

Henseler, J., Ringle, C. M., \& Sarstedt, M. (2015). A new criterion for assessing discriminant validity in variance-based structural equation modeling. Journal of the Academy of Marketing Science, 43(1), 115-135. https://doi.org/10.1007/s11747-014-0403-8

Homburg, C., Schwemmle, M., \& Kuehnl, C. (2015). New Product Design: Concept, Measurement, and Consequences. Journal of Marketing, 79(3), 41-56. https://doi.org/10.1509/jm.14.0199

Hu, L., \& Bentler, P. M. (1999). Cutoff criteria for fit indexes in covariance structure analysis: Conventional criteria versus new alternatives. Structural Equation Modeling: A Multidisciplinary Journal, 6(1), 1-55. https://doi.org/10.1080/10705519909540118

Hur, J. D., Koo, M., \& Hofmann, W. (2015). When Temptations Come Alive: How Anthropomorphism Undermines Self-Control. Journal of Consumer Research, 42(2), ucv017. https://doi.org/10.1093/jcr/ucv017

Jackson, D. L., Gillaspy, J. A., \& Purc-Stephenson, R. (2009). Reporting practices in confirmatory factor analysis: An overview and some recommendations. Psychological Methods, 14(1), 6-23. https://doi.org/10.1037/a0014694

Keller, K. L. (1993). Conceptualizing, Measuring, and Managing Customer-Based Brand Equity. Journal of Marketing, 57(1), 1-22. https://doi.org/10.1177/002224299305700101

Kim, H. C., \& Kramer, T. (2015). Do Materialists Prefer the "Brand-as-Servant"? The Interactive Effect of Anthropomorphized Brand Roles and Materialism on Consumer Responses. Journal of Consumer Research, 42(2), 284-299. https://doi.org/10.1093/jcr/ucv015

Kim, S., \& McGill, A. L. (2011). Gaming with Mr. Slot or Gaming the Slot Machine? Power, Anthropomorphism, and Risk Perception. Journal of Consumer Research, 38(1), 94-107. https://doi.org/10.1086/658148

Kwak, H., Puzakova, M., \& Rocereto, J. F. (2015). Better Not Smile at the Price: The Differential Role of Brand Anthropomorphization on Perceived Price Fairness. Journal of Marketing, 79(4), 56-76. https://doi.org/10.1509/jm.13.0410

Kwak, H., Puzakova, M., \& Rocereto, J. F. (2017). When brand anthropomorphism alters perceptions of justice: The moderating role of self-construal. International Journal of Research in Marketing, 34(4), 851-871. https://doi.org/10.1016/j.ijresmar.2017.04.002

Landwehr, J. R., McGill, A. L., \& Herrmann, A. (2011). It's Got the Look: The Effect of Friendly and Aggressive "Facial" Expressions on Product Liking and Sales. Journal of Marketing, 75(3), 132-146. https://doi.org/10.1509/jmkg.75.3.132

Law, K. S., Wong, C.-S., \& Mobley, W. H. (1998). Toward a Taxonomy of Multidimensional Constructs. The Academy of Management Review, 23(4), 741. https://doi.org/10.2307/259060

Leyens, J.-P., Rodriguez-Perez, A., Rodriguez-Torres, R., Gaunt, R., Paladino, M.-P., Vaes, J., \& Demoulin, S. (2001). Psychological essentialism and the differential attribution of uniquely human emotions to ingroups and outgroups. European Journal of Social Psychology, 31(4), 395-411. https://doi.org/10.1002/ejsp.50

Macinnis, D. J., \& Folkes, V. S. (2017). Humanizing brands: When brands seem to be like me, part of me, and in a relationship with me. Journal of Consumer Psychology, 27(3), 355-374. https://doi.org/10.1016/j.jcps.2016.12.003

MacKenzie, Podsakoff, \& Podsakoff. (2011). Construct Measurement and Validation Procedures in MIS and Behavioral Research: Integrating New and Existing Techniques. MIS Quarterly, 35(2), 293. https://doi.org/10.2307/23044045

May, F., \& Monga, A. (2014). When Time Has a Will of Its Own, the Powerless Don't Have the Will to Wait: Anthropomorphism of Time Can Decrease Patience. Journal of Consumer Research, 40(5), 924-942. https://doi.org/10.1086/673384

McKnight, H. D., \& Chervany, N. L. (2001). Trust and Distrust Definitions: One Bite at a Time. In Trust in Cybersocieties (pp. 27-54). IEEE. https://doi.org/10.1007/3-540-45547-7_3

Meyers-Levy, J., \& Loken, B. (2015). Revisiting gender differences: What we know and what lies ahead. Journal of 
Consumer Psychology, 25(1), 129-149. https://doi.org/10.1016/j.jcps.2014.06.003

Moore, G. (1999). Corporate Moral Agency: Review and Implications. Journal of Business Ethics, 21(4), 329-343. https://doi.org/10.1023/A:1006020214228

Moorman, C., Zaltman, G., \& Deshpande, R. (1992). Relationships between Providers and Users of Market Research: The Dynamics of Trust within and between Organizations. Journal of Marketing Research, 29(3), 314-328. https://doi.org/10.1177/002224379202900303

Mourey, J. A., Olson, J. G., \& Yoon, C. (2017). Products as Pals: Engaging with Anthropomorphic Products Mitigates the Effects of Social Exclusion. Journal of Consumer Research, 44(2), ucx038. https://doi.org/10.1093/jcr/ucx038

Nunnally, J., \& Bernstein, I. (1994). Psychometric Theory. McGraw-Hill, New York. https://doi.org/10.1007/978-14020-9173-5_8

O'Meara, R. (2019). Brands Think They Know "Who" Their Customers Are; The Question Becomes "Who Else?" Retrieved November 8, 2019, from https://www.advertisingweek360.com/brands-think-they-who-theircustomers-are-the-question-becomes-who-else/

Obermiller, C., \& Spangenberg, E. R. (2000). On the Origin and Distinctness of Skepticism toward Advertising. Marketing Letters, 11(4), 311-322. https://doi.org/10.1023/A:1008181028040

Peer, E., Brandimarte, L., Samat, S., \& Acquisti, A. (2017). Beyond the Turk: Alternative platforms for crowdsourcing behavioral research. Journal of Experimental Social Psychology, 70, 153-163. https://doi.org/10.1016/j.jesp.2017.01.006

Puzakova, M., \& Kwak, H. (2017). Should Anthropomorphized Brands Engage Customers? The Impact of Social Crowding on Brand Preferences. Journal of Marketing, 81(6), 99-115. https://doi.org/10.1509/jm.16.0211

Puzakova, M., Kwak, H., \& Rocereto, J. (2009). Pushing the Envelope of Brand and Personality: Antecedents and Moderators of Anthropomorphized Brands. Advances in Consumer Research Volume, 36(732), 413-420.

Puzakova, M., Kwak, H., \& Rocereto, J. F. (2013). When Humanizing Brands Goes Wrong: The Detrimental Effect of Brand Anthropomorphization amid Product Wrongdoings. Journal of Marketing, 77(3), 81-100. https://doi.org/10.1509/jm.11.0510

Raju, S., Unnava, H. R., \& Montgomery, N. V. (2009). The Moderating Effect of Brand Commitment on the Evaluation of Competitive Brands. Journal of Advertising, 38(2), 21-36. https://doi.org/10.2753/JOA0091-3367380202

Reavey, B., Puzakova, M., Larsen Andras, T., \& Kwak, H. (2018). The multidimensionality of anthropomorphism in advertising: the moderating roles of cognitive busyness and assertive language. International Journal of Advertising, 37(3), 440-462. https://doi.org/10.1080/02650487.2018.1438054

Reich, B. J., Beck, J. T., \& Price, J. (2018). Food as Ideology: Measurement and Validation of Locavorism. Journal of Consumer Research, 45(Walmart 2017). https://doi.org/10.1093/jcr/ucy027

Romero, M., \& Craig, A. (2017). Costly Curves: How Human-Like Shapes Can Increase Spending. Journal of Consumer Research, 44(1), ucw080. https://doi.org/10.1093/jcr/ucw080

Russell, C. A., Norman, A. T., \& Heckler, S. E. (2004). The Consumption of Television Programming: Development and Validation of the Connectedness Scale. Journal of Consumer Research, 31(1), 150-161. https://doi.org/10.1086/383431

Sapontzis, S. F. (1981). A Critique of Personhood. Ethics, 91(4), 607-618. https://doi.org/10.1086/292273

Sardana, D., Gupta, N., \& Sharma, P. (2018). Spirituality and Religiosity at the Junction of Consumerism: Exploring Consumer Preference for Spiritual Brands. International Journal of Consumer Studies, 42(6), 724-735.

Sela, A., Wheeler, S. C., \& Sarial-Abi, G. (2012). $<$ em $>$ We $</$ em $>$ Are Not the Same as $<$ em $>$ You and I $</ e m>$ : Causal Effects of Minor Language Variations on Consumers\&\#x2019; Attitudes toward Brands. Journal of Consumer Research, 39(3), 644-661. https://doi.org/10.1086/664972

Spears, N., \& Singh, S. N. (2004). Measuring Attitude toward the Brand and Purchase Intentions. Journal of Current Issues \& Research in Advertising, 26(2), 53-66. https://doi.org/10.1080/10641734.2004.10505164

Srull, T. K., \& Wyer, R. S. (1989). Person memory and judgment. Psychological Review, 96(1), 58-83. https://doi.org/10.1037/0033-295X.96.1.58

Steiger, J. H. (2000). Point Estimation, Hypothesis Testing, and Interval Estimation Using the RMSEA: Some Comments and a Reply to Hayduk and Glaser. Structural Equation Modeling: A Multidisciplinary Journal, 7(2), 149-162. https://doi.org/10.1207/S15328007SEM0702_1

Strizhakova, Y., Coulter, R. A., \& Price, L. L. (2008). The meanings of branded products: A cross-national scale 
development and meaning assessment. International Journal of Research in Marketing, 25(2), 82-93. https://doi.org/10.1016/j.ijresmar.2008.01.001

Tabachnick, B. G., \& Fidell, L. S. (2012). Using Multivariate Statistics. New York: Harper and Row (6th Editio). Boston: Person Education. https://doi.org/10.1037/022267

Tam, K. P., Lee, S. L., \& Chao, M. M. (2013). Saving Mr. Nature: Anthropomorphism enhances connectedness to and protectiveness toward nature. Journal of Experimental Social Psychology, 49(3), 514-521. https://doi.org/10.1016/j.jesp.2013.02.001

Tett, R. P., Fox, K. E., \& Wang, A. (2005). Development and Validation of a Self-Report Measure of Emotional Intelligence as a Multidimensional Trait Domain. Personality and Social Psychology Bulletin, 31(7), 859-888. https://doi.org/10.1177/0146167204272860

Tinsley, H. E. A., \& Tinsley, D. J. (1987). Uses of Factor Analysis in Counseling Psychology Research. Journal of Counseling Psychology, 34(4), 414-424. https://doi.org/10.1037/0022-0167.34.4.414

Tu, L., Khare, A., \& Zhang, Y. (2012). A short 8-item scale for measuring consumers' local-global identity. International Journal of Research in Marketing, 29(1), 35-42. https://doi.org/10.1016/j.ijresmar.2011.07.003

Vandecasteele, B., \& Geuens, M. (2010). Motivated Consumer Innovativeness: Concept, measurement, and validation. International Journal of Research in Marketing, 27(4), 308-318. https://doi.org/10.1016/j.ijresmar.2010.08.004

Vandenberg, R. J., \& Lance, C. E. (2000). A Review and Synthesis of the Measurement Invariance Literature: Suggestions, Practices, and Recommendations for Organizational Research. Organizational Research Methods, 3(1), 4-70. https://doi.org/10.1177/109442810031002

Voorhees, C. M., Brady, M. K., Calantone, R., \& Ramirez, E. (2016). Discriminant validity testing in marketing: an analysis, causes for concern, and proposed remedies. Journal of the Academy of Marketing Science, 44(1), 119-134. https://doi.org/10.1007/s11747-015-0455-4

Wan, E. W., Chen, R. P., \& Jin, L. (2017). Judging a Book by Its Cover? The Effect of Anthropomorphism on Product Attribute Processing and Consumer Preference. Journal of Consumer Research, 43(6), 1008-1030. https://doi.org/10.1093/jcr/ucw074

Watson, G. F., Beck, J. T., Henderson, C. M., \& Palmatier, R. W. (2015). Building, measuring, and profiting from customer loyalty. Journal of the Academy of Marketing Science, 43(6), $790-825$. https://doi.org/10.1007/s11747-015-0439-4

Waytz, A., Cacioppo, J., \& Epley, N. (2010). Who Sees Human? The Stability and Importance of Individual Differences in Anthropomorphism. Perspectives on Psychological Science, 5(3), $219-232$. https://doi.org/10.1177/1745691610369336

Waytz, A., Gray, K., Epley, N., \& Wegner, D. M. (2010). Causes and consequences of mind perception. Trends in Cognitive Sciences, 14(8), 383-388. https://doi.org/10.1016/j.tics.2010.05.006

Waytz, A., Morewedge, C. K., Epley, N., Monteleone, G., Gao, J.-H., \& Cacioppo, J. T. (2010). Making sense by making sentient: Effectance motivation increases anthropomorphism. Journal of Personality and Social Psychology, 99(3), 410-435. https://doi.org/10.1037/a0020240

Wells, W. D. (1993). Discovery-Oriented Consumer Research. Journal of Consumer Research, $19(4), 489$. https://doi.org/10.1086/209318

Widaman, K. F. (1985). Hierarchically Nested Covariance Structure Models for Multitrait-Multimethod Data. Applied Psychological Measurement, 9(1), 1-26. https://doi.org/10.1177/014662168500900101

Worthington, R. L., \& Whittaker, T. A. (2006). Scale Development Research. The Counseling Psychologist, 34(6), 806838. https://doi.org/10.1177/0011000006288127

Yoo, B., \& Donthu, N. (2001). Developing and validating a multidimensional consumer-based brand equity scale. Journal of Business Research, 52(1), 1-14. https://doi.org/10.1016/S0148-2963(99)00098-3 


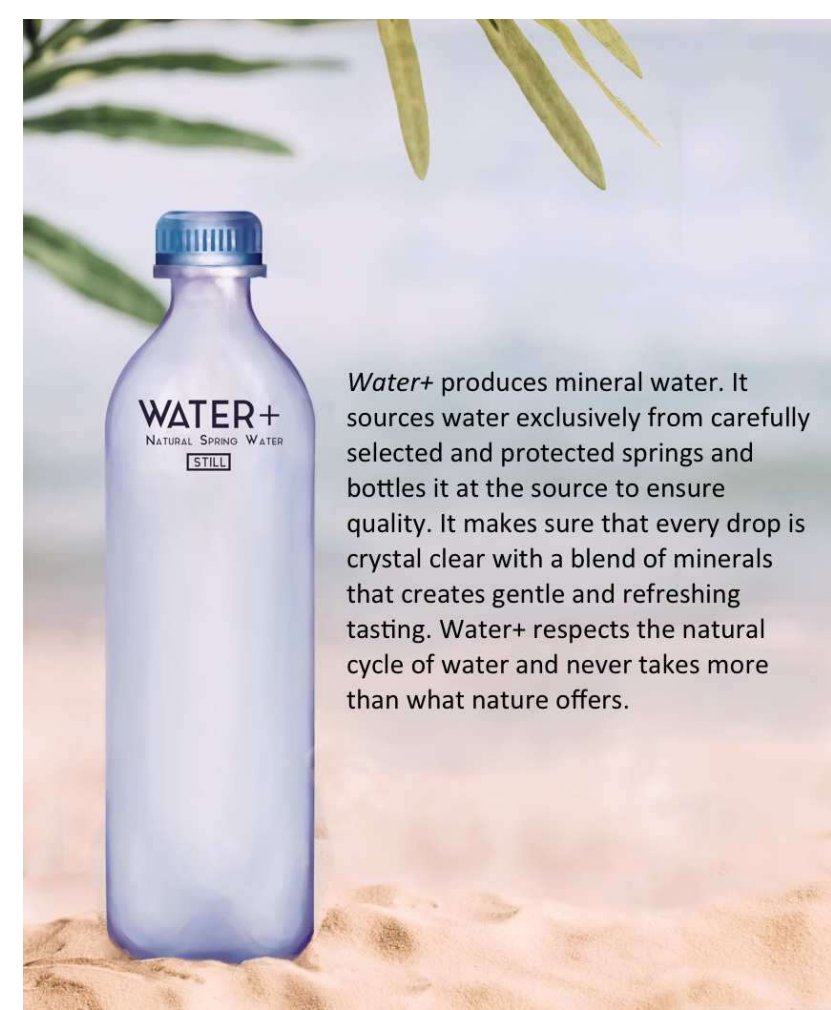

(a) Non-anthropomorphised stimulus

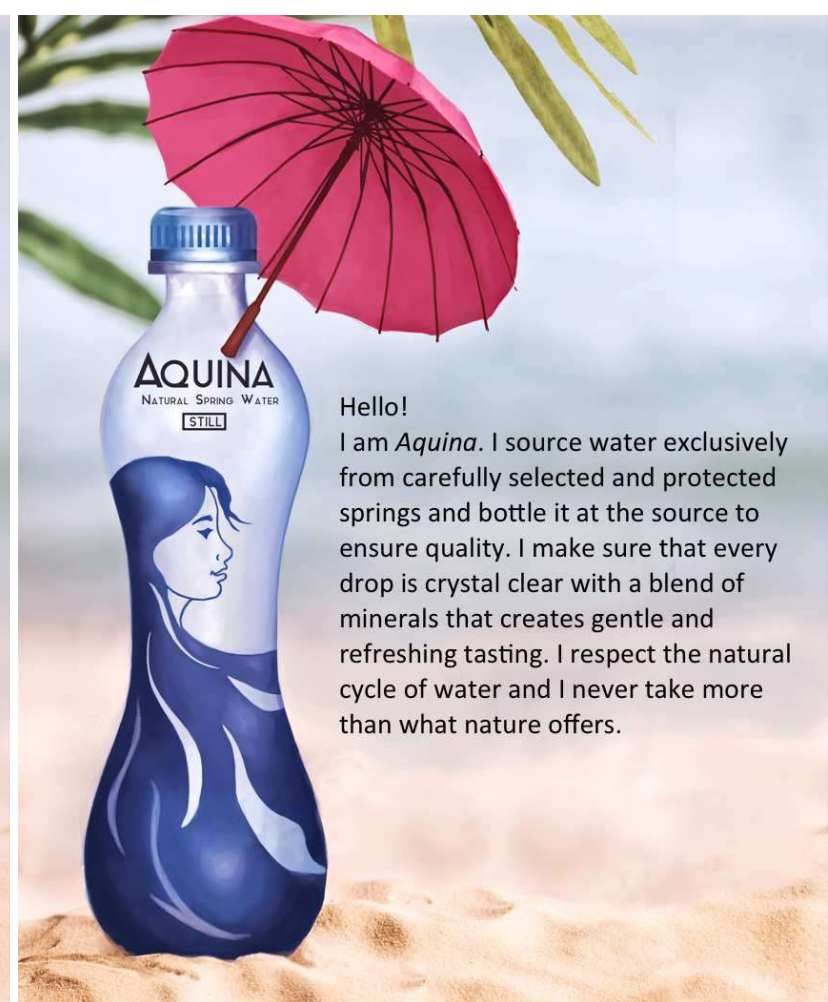

(b) Anthropomorphised stimulus

Figure 1: Conditions used in Study 1 and 2. 


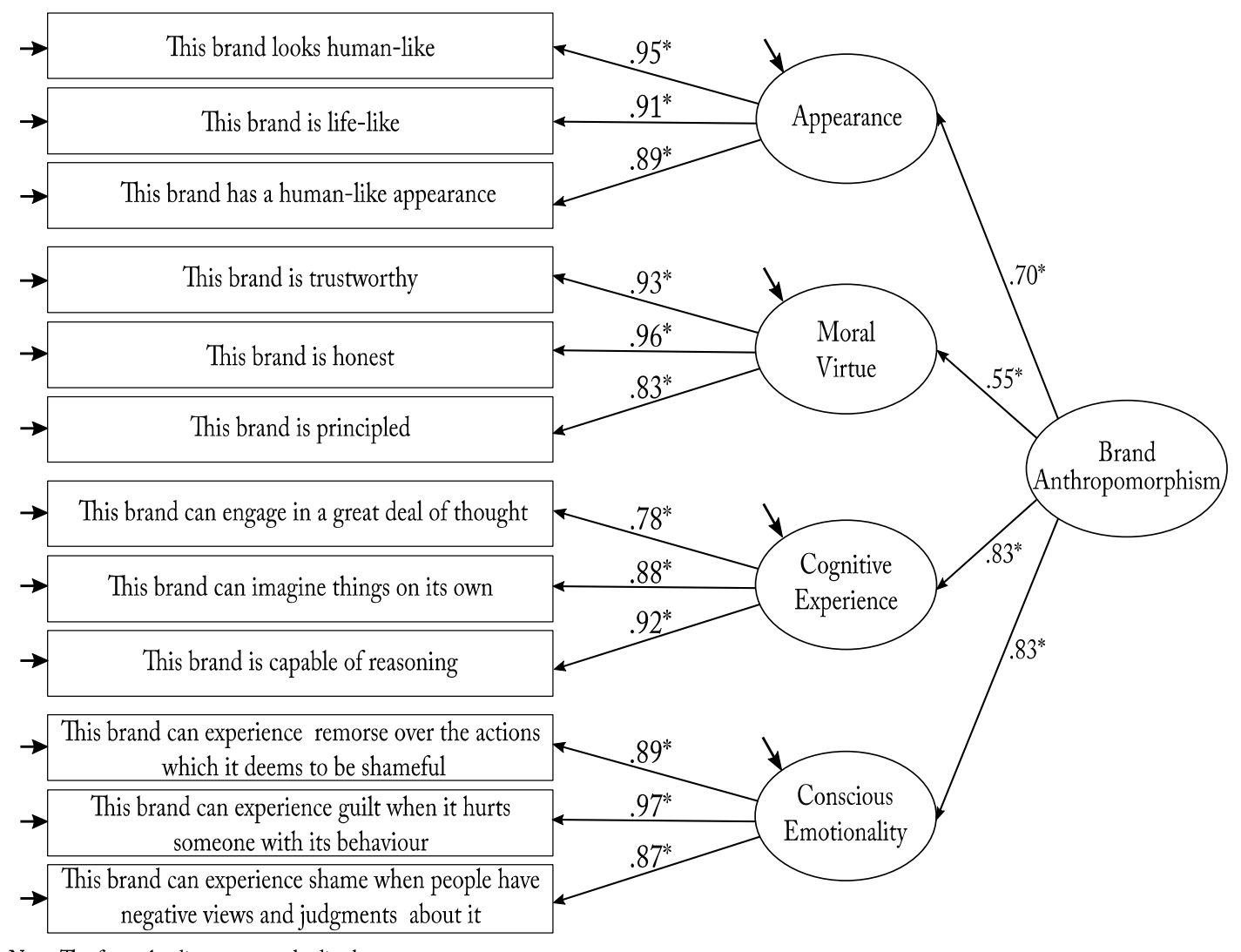

Note: The factor loadings are standardised. ${ }^{*} \mathrm{p}<.001$

Figure 2: Graphical representation of the final higher-order BASC. 
Table 1: Items, descriptive statistics, convergent and discriminant validity of the dimensions.

\begin{tabular}{|c|c|c|c|}
\hline BASC dimensions and items & $\lambda$ & $M$ & $S D$ \\
\hline \multicolumn{4}{|l|}{ Appearance } \\
\hline This brand looks human-like & .91 & 3.62 & 1.80 \\
\hline This brand is life-like & .78 & 3.50 & 1.73 \\
\hline This brand has human-like appearance & .94 & 3.57 & 1.82 \\
\hline \multicolumn{4}{|l|}{ Moral Virtue } \\
\hline This brand is trustworthy & .93 & 4.36 & 1.51 \\
\hline This brand is honest & .96 & 4.37 & 1.47 \\
\hline This brand is principled & .90 & 4.51 & 1.56 \\
\hline \multicolumn{4}{|l|}{ Cognitive Experience } \\
\hline This brand can engage in a great deal of thought & .94 & 3.47 & 1.80 \\
\hline This brand can imagine things on its own & .93 & 3.30 & 1.75 \\
\hline This brand is capable of reasoning & .95 & 3.37 & 1.79 \\
\hline \multicolumn{4}{|l|}{ Conscious Emotionality } \\
\hline This brand can experience remorse over actions which it deems to be shameful & .95 & 3.12 & 1.74 \\
\hline This brand can experience compassion for people who feel down ${ }^{a}$ & .94 & 3.09 & 1.70 \\
\hline This brand can experience guilt when it hurts someone with its behaviour & .92 & 3.10 & 1.80 \\
\hline $\begin{array}{l}\text { This brand can experience shame when people have negative views and judgments } \\
\text { about it }\end{array}$ & .96 & 3.05 & 1.72 \\
\hline
\end{tabular}

Convergent and discriminant validity of the dimensions

\begin{tabular}{|c|c|c|c|c|c|c|c|c|}
\hline Construct & $\mathrm{CR}$ & AVE & 1 & 2 & 3 & 4 & $M$ & $S D$ \\
\hline 1. Appearance & .91 & .77 & .88 & & & & 3.57 & 1.64 \\
\hline 2. Moral virtue & .95 & .87 & $.35(.39)$ & .93 & & & 4.41 & 1.44 \\
\hline 3. Cognitive experience & .96 & .89 & $.49(.52)$ & $.63(.64)$ & .94 & & 3.38 & 1.71 \\
\hline 4. Conscious emotionality & .97 & .89 & $.49(.52)$ & $.56(.58)$ & $.87(.89)$ & .94 & 3.09 & 1.66 \\
\hline
\end{tabular}

Note: The square root of AVE of each construct is in bold and reported on the diagonal; HTMT ratios are reported in the parentheses.

"This brand" can be changed for a specific name of the brand.

Correlations are significant at $p<.001$ (two-tailed).

All factor loadings are significant at $p<.001$.

a The item was dropped in Study 3. 
Table 2: Model comparison.

\begin{tabular}{|c|c|c|c|c|c|c|c|c|c|}
\hline Model & Merged Components & $\chi^{2}(d f)$ & CFI & TLI & IFI & RMSEA & SRMR & $\Delta_{i}$ & $\Delta \mathrm{CFI}$ \\
\hline 4 Factors & - & $138.9(59)$ & .99 & .98 & .99 & .058 & .032 & - & - \\
\hline 3 Factors & CGE and CNE & $629.8(62)$ & .91 & .89 & .91 & .151 & .053 & 484.91 & .08 \\
\hline 3 Factors & CGE and APP & $808.3(62)$ & .88 & .85 & .86 & .173 & .099 & 663.41 & .10 \\
\hline 3 Factors & CGE and MRV & $1039.8(62)$ & .85 & .81 & .85 & .198 & .090 & 894.84 & .14 \\
\hline 3 Factors & CNE and MRV & $1164.7(62)$ & .83 & .79 & .83 & .210 & .110 & 1019.74 & .16 \\
\hline 3 Factors & CNE and APP & $827.4(62)$ & .88 & .85 & .88 & .175 & .105 & 682.49 & .11 \\
\hline 3 Factors & APP and MRV & $940.3(62)$ & .86 & .83 & .86 & .188 & .153 & 795.41 & .12 \\
\hline 2 Factors & CGE, CNE and MRV & $1590.3(64)$ & .76 & .71 & .76 & .244 & .107 & 1441.35 & .23 \\
\hline 2 Factors & CGE, CNE and APP & $1300.4(64)$ & .81 & .77 & .81 & .219 & .109 & 1151.51 & .18 \\
\hline 2 Factors & CGE, MRV and APP & $1704.1(64)$ & .75 & .69 & .75 & .252 & .129 & 1555.19 & .24 \\
\hline 2 Factors & CNE, MRV and APP & $1844.7(64)$ & .72 & .66 & .72 & .263 & .145 & 1695.81 & .26 \\
\hline 1 Factor & All & $2254.4(65)$ & .66 & .59 & .66 & .289 & .141 & 2103.52 & .33 \\
\hline
\end{tabular}

Note: $\Delta_{i}$ is calculated with respect to the baseline model (4 Factors) which is the best-fitting model with the lowest AIC (AIC $=202.92$ ). $\mathrm{APP}=$ appearance; $\mathrm{MRV}=$ moral virtue; $\mathrm{CGE}=$ cognitive experience; $\mathrm{CNE}=$ conscious emotionality. 
Table 3: Performance of the BASC.

\begin{tabular}{|c|c|c|c|c|}
\hline & Study 2 & Study 3 & Study 4 & Study 5 \\
\hline Sample size & 403 & 320 & 334 & 146 \\
\hline Number of items & 13 & 12 & 12 & 12 \\
\hline \multicolumn{2}{|l|}{ Four factorial correlated model } & \multicolumn{3}{|c|}{ Items loadings } \\
\hline Appearance & $.78-.94$ & $.88-.95$ & $.85-.91$ & $.91-.92$ \\
\hline Moral Virtue & $.90-.96$ & $.83-.96$ & $.77-.94$ & $.86-.92$ \\
\hline Cognitive Experience & $.93-.95$ & $.79-.91$ & $.77-.87$ & $.78-.81$ \\
\hline Conscious Emotionality & $.92-.96$ & $.88-.96$ & $.86-.90$ & $.85-.96$ \\
\hline \multicolumn{5}{|l|}{ CR; AVE } \\
\hline Appearance & $.91 ; .77$ & $.94 ; .84$ & $.92 ; .78$ & $.94 ; .84$ \\
\hline Moral Virtue & $.95 ; .87$ & $.93 ; .83$ & $.89 ; .73$ & $.91 ; .77$ \\
\hline Cognitive Experience & $.96 ; .89$ & $.90 ; .75$ & $.86 ; .67$ & $.84 ; .64$ \\
\hline Conscious Emotionality & $.97 ; .89$ & $.94 ; .83$ & $.93 ; .81$ & $.94 ; .83$ \\
\hline \multicolumn{5}{|l|}{ Factor analysis } \\
\hline$\chi^{2}(d f)$ & $138.9(59)$ & $183.6(48)$ & $167.1(48)$ & $83.8(48)$ \\
\hline CFI & .99 & .96 & .96 & .98 \\
\hline TLI & .98 & .95 & .95 & .97 \\
\hline IFI & .99 & .96 & .96 & .98 \\
\hline RMSEA & .058 & .094 & .086 & .072 \\
\hline SRMR & .032 & .057 & .048 & .046 \\
\hline \multicolumn{5}{|l|}{ Second-order factorial model } \\
\hline \multicolumn{5}{|l|}{ Factor loadings } \\
\hline Appearance & .52 & .70 & .56 & .64 \\
\hline Moral Virtue & .64 & .54 & .52 & .69 \\
\hline Cognitive Experience & .97 & .84 & .91 & .97 \\
\hline Conscious Emotionality & .90 & .83 & .80 & .75 \\
\hline CLVR; AVE & $.85 ; .61$ & $.82 ; .54$ & $.80 ; .51$ & $.85 ; .60$ \\
\hline$M(\mathrm{SD})$ & $3.57(1.34)$ & $4.17(1.19)$ & $4.12(1.04)$ & $4.17(1.18)$ \\
\hline \multicolumn{5}{|l|}{ Factor analysis } \\
\hline$\chi^{2}(d f)$ & $141.4(61)$ & $185.3(50)$ & $170.9(50)$ & $90.2(50)$ \\
\hline CFI & .99 & .96 & .96 & .97 \\
\hline TLI & .98 & .95 & .95 & .96 \\
\hline IFI & .99 & .96 & .96 & .97 \\
\hline RMSEA & .057 & .092 & .085 & .074 \\
\hline SRMR & .035 & .058 & .052 & .052 \\
\hline
\end{tabular}

Note: AVE = Average Variance Extracted; CR = Composite Reliability; CLVR = Composite Latent Variable Reliability; M = Mean; SD = Standard Deviation.

All item and second-order factor loadings are significant at $p<.001$. 
Table 4: Summary of fit statistics for the BASC gender invariance models.

\begin{tabular}{lcccccccc}
\hline Model & $\chi^{2}$ & $d f$ & CFI & Models & $\Delta \chi^{2}$ & $\Delta d f$ & $p$ & $\Delta$ CFI \\
\hline M1-Configural invariance & 241.44 & 100 & .96 & & & & & \\
M2-Invariance of 1st order factor loadings & 245.20 & 108 & .96 & 2 vs.1 & 3.76 & 8 & .89 & .00 \\
M3-Invariance of 2nd order factor loadings & 246.29 & 111 & .96 & $3 \mathrm{vs.2}$ & 1.09 & 3 & .79 & .00 \\
M4-Invariance of 1st order intercepts & 253.80 & 119 & .96 & 4 vs.3 & 7.51 & 8 & .48 & .00 \\
M5-Invariance of 2nd order intercepts & 261.26 & 123 & .96 & 5 vs.4 & 7.46 & 4 & .11 & .00 \\
M6-Invariance of disturbances 1st order factors & 271.26 & 127 & .96 & 6 vs.5 & 9.99 & 4 & .04 & .00 \\
M7-Invariance of measurement residuals & 294.47 & 139 & .96 & 7 vs.6 & 23.22 & 12 & .03 & .00 \\
\hline
\end{tabular}

Table 5: Descriptive statistics, convergent and discriminant validity of the constructs.

\begin{tabular}{|c|c|c|c|c|c|c|c|c|c|}
\hline Construct & $\mathrm{CR}$ & AVE & 1 & 2 & 3 & 4 & 5 & $M$ & $S D$ \\
\hline 1. Brand anthropomorphism & .80 & .51 & .71 & & & & & 4.12 & 1.04 \\
\hline 2. Brand loyalty & .92 & .79 & $.41(.40)$ & .89 & & & & 3.41 & 1.62 \\
\hline 3. Brand affect & .95 & .87 & $.48(.49)$ & $.69(.68)$ & .93 & & & 4.46 & 1.37 \\
\hline 4. Brand attitude & .95 & .80 & $.55(.55)$ & $.55(.55)$ & $.72(.73)$ & .90 & & 5.12 & 1.36 \\
\hline 5. Self-brand connection & .94 & .69 & $.61(.60)$ & $.73(.74)$ & $.69(.71)$ & $.64(.67)$ & .83 & 3.34 & 1.38 \\
\hline
\end{tabular}

Note: The square root of AVE of each construct is in bold and reported on the diagonal; HTMT ratios are reported in the parentheses. CRVL is reported for brand anthropomorphism.

Correlations are significant at $p<.001$ level (two-tailed).

Table 6: Predictive and incremental validity of the BASC.

\begin{tabular}{llcccc}
\hline Dependent variable & Measure & $\begin{array}{c}\beta \\
\text { step 1 }\end{array}$ & $\begin{array}{c}\beta \\
\text { step 2 }\end{array}$ & $R^{2}$ & $\Delta R^{2}$ \\
\hline $\begin{array}{l}\text { Brand commitment } \\
\text { Step 1 }\end{array}$ & BAMA & $.33^{* * *}$ & & & \\
Step 2 & BASC & & $.39^{* * *}$ & .17 & $.07^{* * *}$ \\
$\begin{array}{l}\text { Brand trust } \\
\text { Step 1 }\end{array}$ & & & & & \\
Step 2 & BAMA & $.37^{* * *}$ & & .14 & \\
\hline
\end{tabular}

Note: Standardised coefficients.

$* * * p \leq .001$ 